\title{
Large-scale modelling of soil-pipe interaction during large amplitude cyclic movements of partially embedded pipelines
}

\author{
C.Y. Cheuk, D.J. White, and M.D. Bolton
}

\begin{abstract}
As the development of offshore hydrocarbons moves into deeper water, pipelines form an increasingly significant part of the required infrastructure. High-temperature high-pressure pipelines must be designed to accommodate thermal expansion and potential lateral buckling. A novel design approach is to control the formation of pre-engineered lateral buckles to relieve the expansion. The amplitude of these buckles is typically several pipe diameters. Assessment of the force-displacement interaction between the on-bottom pipeline and the seabed is crucial for design. A series of large-scale plane strain model tests has been conducted to measure the response of a pipe segment partially embedded in soft clay, during large amplitude cyclic movements, mimicking consecutive thermal expansion and contraction at a bend in a pipeline. Four key stages in the force-displacement response have been identified: (i) breakout, (ii) suction release, (iii) resistance against a steadily growing active berm, and (iv) additional resistance during collection of a pre-existing dormant berm. A simple upper bound solution is proposed to model the observed response. This solution captures the experimental trends including growth of the active berm and collection of dormant berms. This approach is the first attempt to quantitatively model the mechanisms underlying the response during large-displacement lateral sweeps of an on-bottom pipeline, accounting for the growth of soil berms.
\end{abstract}

Key words: pipeline, thermal buckling, clay, physical modelling, upper bound solution.

Résumé : Comme l'exploitation offshore des hydrocarbures se déplace vers les eaux plus profondes, les pipelines constituent de plus en plus une part importante de l'infrastructure requise. Les pipelines à haute température et à haute pression doivent être conçus pour accommoder l'expansion thermique et le flambage latéral potentiel. Une nouvelle approche de conception consiste à contrôler la formation de flambages latéraux conçus pour soulager l'expansion. L'amplitude de ces flambages est typiquement de plusieurs diamètres du tuyau. L'évaluation de l'interaction force-déplacement entre le pipeline sur le fond et le lit de la mer est crucial pour la conception. Une série d'essais sur modèle à grande échelle en déformation plane a été réalisée pour mesurer la réponse d'un segment de tuyau partiellement enfoui dans l'argile molle, au cours de mouvements cycliques de grande amplitude, imitant l'expansion thermique et la contraction résultantes à un coude dans le pipeline. On a identifié quatre étapes fondamentales dans la réaction force-déplacement : $(i)$ l'éclatement, (ii) le relâchement de pression, (iii) la résistance contre une berme active qui croît régulièrement, et (iv) la résistance additionnelle durant la mobilisation de la berme dormante existante. On propose une solution simple de limite supérieure pour modéliser la réponse observée. Cette solution capte les tendances expérimentales incluant la croissance de la berme active, et la mobilisation des bermes dormantes. Cette approche est la première tentative pour modéliser quantitativement le mécanisme sous-tendant la réponse durant les grands mouvements latéraux à fort déplacement d'un pipeline reposant sur le fond, tenant compte de la croissance de bermes de sol.

Mots-clés : pipeline, flambage thermique, argile, modélisation physique, solution à limite supérieure.

[Traduit par la Rédaction]

\section{Introduction}

\section{Offshore pipelines}

As the development of offshore hydrocarbons moves into deeper water, pipelines form an increasingly significant part of the required infrastructure. Subsea wellheads are increasingly favoured over fixed or floating above-water structures.
These subsea facilities are often connected by pipelines to a single processing platform, serving a widely distributed network of wells. This production platform may in turn be connected to shore by a long export pipeline, more than $100 \mathrm{~km}$ in length. These pipelines operate at high temperature and pressure, and so they must be designed to accommodate thermal expansion and potential lateral buckling.

Received 27 July 2006. Accepted 30 April 2007. Published on the NRC Research Press Web site at cgj.nrc.ca on 5 October 2007.

C.Y. Cheuk. ${ }^{1}$ Department of Civil Engineering, The University of Hong Kong, Pokfulam Road, Hong Kong.

D.J. White. Centre for Offshore Foundation Systems, The University of Western Australia, 35 Stirling Highway, Crawley, Perth WA6009, Australia.

M.D. Bolton. Schofield Centre, Department of Engineering, The University of Cambridge, High Cross, Madingley Road, Cambridge, CB3 OEL, UK.

${ }^{1}$ Corresponding author (e-mail: cycheuk@hkucc.hku.hk). 


\section{Thermal buckling}

The behaviour of offshore pipelines used for transportation of oil and gas involves complex interaction between the seabed and the pipeline. In deep water conditions, thermal buckling is one of the key problems that pipeline designers must tackle (Perinet and Frazer 2006). Hydrocarbons must be transported at high temperature and pressure to ease the flow and prevent solidification of the wax fractions. These extreme operating conditions cause thermal expansion in the pipe, which is hindered by side friction at the soil-pipe interface as well as restraint at the end connections that hold the pipe in position. Consequently, axial compressive stresses are generated leading to a vulnerability to buckling in the horizontal direction. This mode of pipeline failure has been reported by Pasqualino et al. (2001) and McKinnon et al. (2001).

The risk of buckling can be minimized either by reducing the axial load in the pipeline using expansion spools or by increasing the lateral restraint through trenching and burial. The passive resistance of the sidewalls of the trench prevents the pipeline from buckling in the lateral direction. This method has proven to be effective, but is becoming less viable as the operating temperatures and pressures increase further and as developments move into deeper water where trenching is not viable.

\section{Lateral buckling design}

A more cost-effective design method is to relieve the axial stress by controlling the formation of buckles along the pipeline. By laying the pipeline in a snaking pattern on the seabed, buckles are allowed to form at prescribed locations so as to relieve the axial stress. The imposed initial imperfections, as well as the seabed surface topography, govern the location and the size of the buckles that develop. These buckles must be engineered such that a sufficient length of pipe feeds into the buckle to relieve the axial stress, without generating excessive bending within the buckle. The typical lateral pipe movement within an engineered buckle is several diameters.

This approach offers an elegant and cost-effective solution to tackle the thermal buckling of pipelinesand has been adopted by the offshore industry. Case studies of lateral bucking are reported by Kaye et al. (1995), Nystrom et al. (2002), and Harrison et al. (2003). Mitigation measures for thermal loading of offshore pipelines, including controlled lateral buckling, are reviewed by Perinet and Frazer (2006). Although this novel design approach offers potential benefits to pipeline engineering, a better understanding of the interaction between the seabed and an on-bottom pipeline is needed for safe and economical design. The cases of full bore pipeline failure due to lateral buckling reported by McKinnon et al. (2001) and Pasqualino et al. (2001) demonstrate the design challenges and potential risk associated with this innovative approach.

When laid on the seabed, a pipeline penetrates into the soil. The amount of initial penetration is dictated by the pipe weight and the external disturbance imposed on the pipe during installation. To release the axial stress upon heating, the bends along the partially embedded pipeline have to overcome the soil restraint and displace laterally. The required breakout resistance is a key design parameter governing the initiation of lateral buckles. In addition, the lateral resistance exerted on the pipeline at large displacements is a significant governing parameter as it controls the amount that a particular buckle can develop. Over a typical life span of 20 years, a pipeline may be subjected to 100-1000 heating and cooling cycles due to changing operating conditions and shutdowns. These cycles of expansion and contraction cause cyclic lateral movements of the partially embedded pipeline. The soil geometry governing the overall behaviour changes continuously in each cycle, with soil berms growing ahead of the laterally sweeping pipe. All of these factors need to be considered in design. When the method is applied in shallow water, the impact on soil geometry caused by external disturbance such as ocean currents and sediment transport should also be taken into account.

Previous research into the soil resistance acting on seabed pipelines has been primarily concerned with pipeline stability under hydrodynamic loading (e.g., Verley and Lund 1995; AGA 1998). The aim has been to estimate the minimum support offered to a pipe by the surrounding soil: this quantity is referred to as the breakout resistance. Conventional design practice has been to assume frictional behaviour, such that the estimated breakout resistance is proportional to the pipe weight. Recommended "friction factors" lie in the range of 0.2-0.8 (Lyons 1973; Brennodden et al. 1986; Wagner et al. 1989). More sophisticated models use a framework of work-hardening plasticity to create models for the generalized response of a pipe resting on soil under combined V-H loading (Schotman and Stork 1987; Zhang et al. 2002). These plasticity based models have been validated by centrifuge experiments (Zhang et al. 2002), but the pipe displacement was limited to half a pipe diameter. Large amplitude cyclic pipe movements have not been considered, and so there is little understanding of the behaviour relevant to lateral buckling design.

\section{Objectives}

To improve the understanding of lateral soil-pipeline interaction and aid the development of improved models for predicting the response, an experimental study was conducted as part of the SAFEBUCK Joint Industry Project. The study focussed on the lateral force exerted on a pipeline undergoing cyclic thermal loading and unloading, causing cycles of lateral sweeping across the seabed. The problem was idealized in plane strain conditions using a pipe section cut off from a prototype pipeline to represent the conditions within a pipeline buckle. Typical pipelines have an outer diameter in the range of 4-30 inches (100-750 $\mathrm{mm}$ ). These dimensions allow the investigation to be carried out in near-field scale conditions. The large-scale tests were conducted in a steel tank with a Perspex window fitted on the front face. E-grade kaolin clay, and a very soft seabed clay collected from the Gulf of Guinea off the coast of West Africa, were used to model the seabed. A shear strength profile similar to the in situ condition was achieved by vacuum consolidation. The resulting shear strength profile was characterized by a laboratory-scale T-bar penetrometer.

The key task of the investigation was measurement of the lateral soil resistance exerted on the partially embedded pipe section and the associated vertical pipe movement during large-amplitude cyclic sweeping under a constant vertical force. The tests were conducted in fully submerged conditions, but the influence of waves and currents, and their ef- 
Fig. 1. General arrangement of lateral pipe-soil interaction tests.

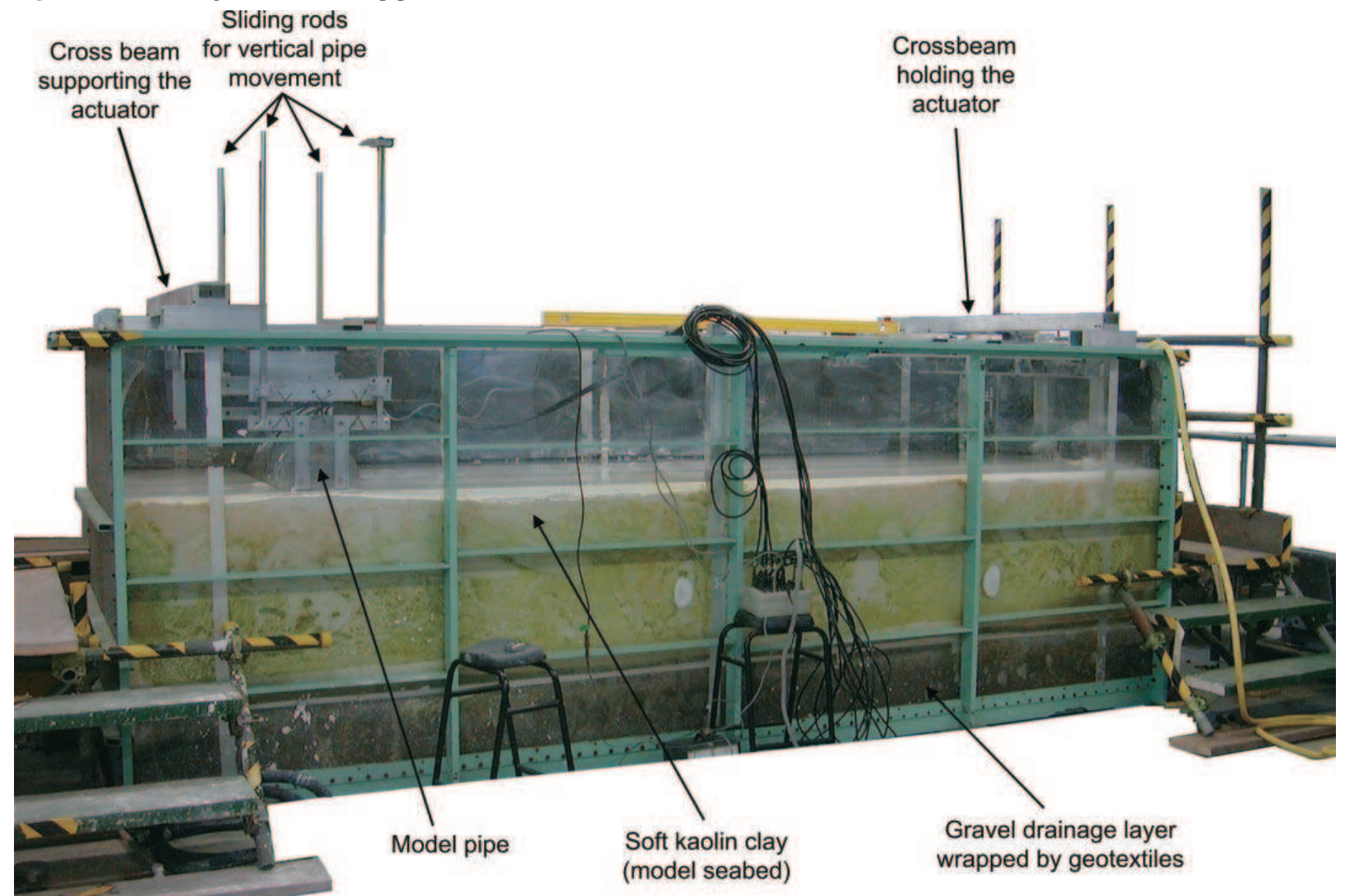

fect on the seabed topography around the pipeline, is beyond the scope of the present study. In deepwater conditions, the hydrodynamic action due to waves and currents is generally insufficient to cause the erosion of soil berms, but this possibility must be considered in shallow water applications.

\section{Experimental methodology}

\section{Test tank}

A test tank with inner dimensions of $4.5 \mathrm{~m}$ (length) $\times$ $1.25 \mathrm{~m}$ (width) $\times 1.5 \mathrm{~m}$ (height) was used to contain the model seabed soil (Fig. 1). The test tank is watertight and has a drainage outlet in one end wall at the base. The model seabed was created by vacuum consolidation from soil slurry until the target shear strength was achieved. To facilitate drainage during vacuum consolidation, a perforated drainage pipe runs the length of the tank, connected to the outlet. Two tonnes of $10 \mathrm{~mm}$ gravel were placed into the base of the tank. This $200 \mathrm{~mm}$ thick gravel layer formed a drainage blanket facilitating water flow beneath the clay during vacuum consolidation. Two layers of geotextile were placed on top of the gravel to prevent mixing with the clay. For the tests conducted on the West African clay, the amount of gravel was increased to $6 \mathrm{t}$ so as to raise the mudline level to a convenient working level, due to the limited supply of the test soil.

\section{Actuator}

The actuator was devised to impose horizontal pipe movement under constant vertical load - simulating the selfweight of the pipe - such that the pipe was free to move vertically during lateral sweeping.

The arrangement of the actuator is shown schematically in Fig. 2. The actuator consists of two $4.2 \mathrm{~m}$ long linear guides with belt-driven carriages. The horizontal movement is controlled by a stepper motor connected through a high-ratio gearbox to the belt drive. A crossbeam is mounted on the two carriages of the actuator through a pair of aluminium channel sections. The crossbeam holds the model pipe through four vertical sliding rods via bearings. The connection between the crossbeam and the channel sections can accommodate horizontal relative movement, which allows the horizontal load applied to the pipe be measured by the load cells attached to the crossbeam as shown in the inset diagrams in Fig. 2. The weight of the crossbeam is not carried through the load cells, but through a pretensioned spring (inset diagrams in Fig. 2). Lubricated polytetrafluoroethylene (PTFE) sheets are used to ensure that the compression between the crossbeam and the channel sections creates only minimal horizontal friction. Calibration tests were conducted to confirm that this arrangement provided accurate measurements of horizontal load with minimal errors due to friction. The load cells on the two channel sections were calibrated 
Fig. 2. Schematic diagram of the actuator for lateral sweeping.

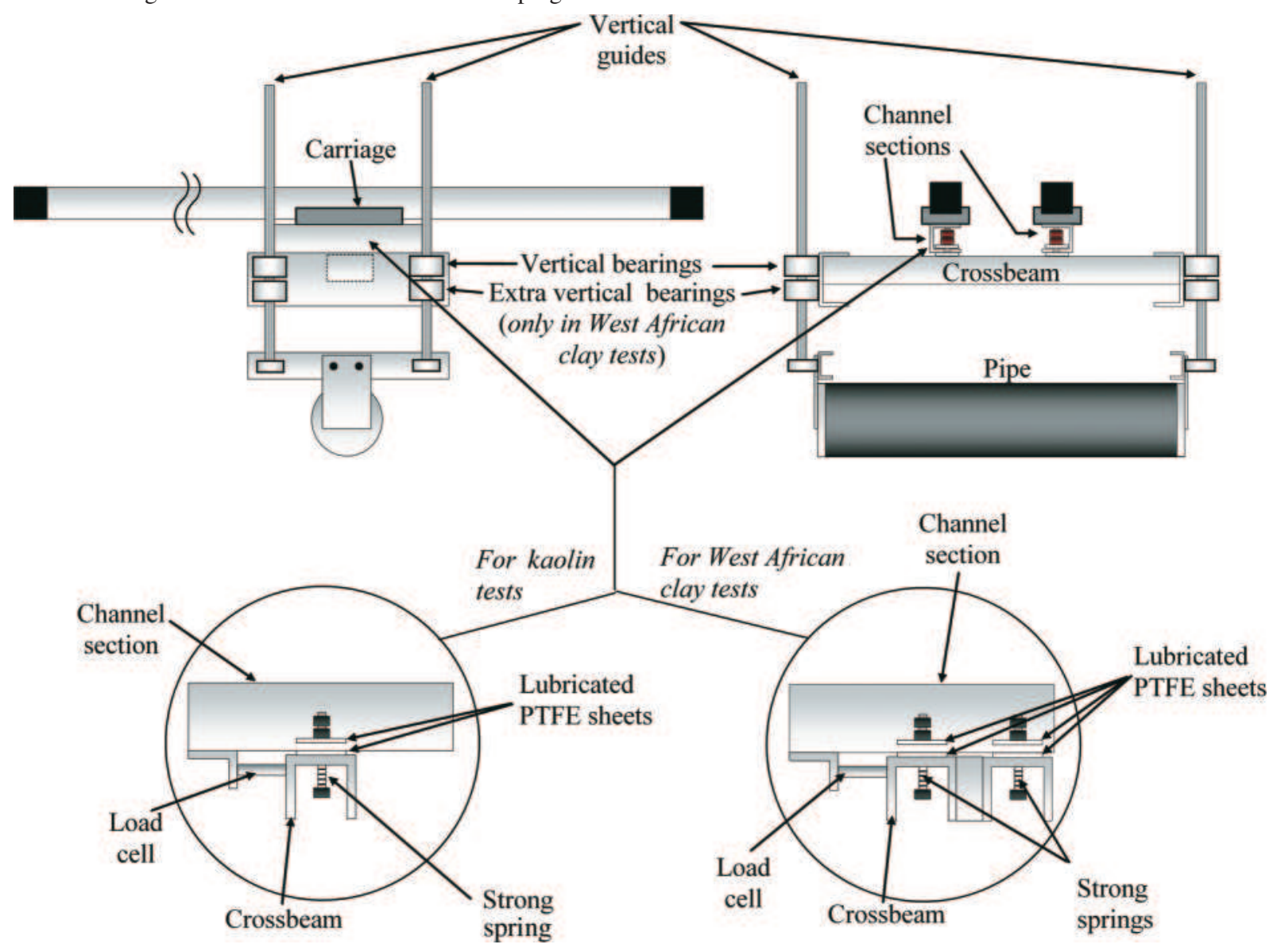

after assembly. The hysteresis created by the friction between the PTFE sheets was found to be less than $0.02 \mathrm{kN}$.

To measure the horizontal pipe displacement, a laser sensor is mounted at the tank wall, using the crossbeam of the carriage as a target to record the horizontal pipe movement. The vertical pipe movement is measured by another laser sensor mounted on one end of the crossbeam. This laser sensor measures the relative vertical movement between the vertical sliding rods and the crossbeam.

The vertical motion of the pipe was observed to be slightly jerky, showing stick-slip behaviour during the leftward sweeps of the first two tests on kaolin (tests JIP2 and JIP3). This observation indicates that some friction existed in the vertical sliding shafts. As shown in Fig. 2, only one bearing was used for each vertical guide in the kaolin tests. Freedom for the vertical shaft to rotate about the single bearing was the major reason for the creation of vertical friction during sweeping. The actuator was therefore slightly modified to enhance the rigidity of the mechanism for the tests on West African clay. An extra pair of bearings was attached to each end of the crossbeam in the actuator. With two bearings supporting each vertical guide, the stick-slip response was eliminated.

\section{Model pipe sections}

Three model pipes of varying size and weight were used in this study (Table 1). The pipes were coated with threelayer, fusion-bonded polyethylene (PE) and fitted with alu- minium end plates. When each pipe was attached to the actuator for the sweeping stage, the self-weight was increased by the two pairs of vertical guides. Table 1 shows the pipe weight in each test during placement on the model seabed (when the water level was at the seabed surface) and at the onset of sweeping (when the pipe was submerged and attached to the actuator). In the second kaolin test (test JIP3), the submerged pipe weight was reduced by filling the pipe with closed cell foam.

The pipe sections were $\sim 1 \mathrm{~m}$ in length (Table 1 ), leaving a gap of $\sim 125 \mathrm{~mm}$ on each side of the pipe during the experiment. From the measured soil strength and pipe embedment, which will be presented in the next section, the maximum frictional resistance arising from end effects is estimated to be $\sim 50 \mathrm{~N}$ (assuming that the pipe-soil interface mobilizes the full soil shear strength). This would occur only in the first part of the first sweep of each test due to the high initial pipe embedment. This would represent a minimal contribution of $5 \%-10 \%$ of the peak horizontal resistance due to end effects, which would not affect the overall pattern of behaviour.

To capture the pore pressure in the soil against the pipe induced by lateral sweeping, six pore pressure transducers (PPTs) were installed in the pipe wall for test JIP3. The locations of the PPTs are shown in Fig. 3.

For the tests conducted on West African clay, Pipes 2 and 3 were used. Pipe 2, made from steel, was about two and a half times heavier than Pipe 3, which was made from aluminium alloy and filled with closed cell foam. 
Table 1. Properties of the model pipes.

\begin{tabular}{llll}
\hline & Pipe 1 & Pipe 2 & Pipe 3 \\
\hline Test & JIP2 and JIP3 & WA1 and WA2 & WA5 \\
Outer diameter (m) & 0.283 & 0.174 & 0.172 \\
Wall thickness (mm) & 11.4 & 18.3 & 12.7 \\
Overall length (m) & 0.98 & 0.99 & 0.99 \\
Submerged pipe weight during placement (N) & 566 (JIP2) 724 (JIP3) & 632 (WA1) 491 (WA2) & 266 \\
Submerged pipe weight during sweeping & 638 (JIP2) 329 (JIP3) & 685 (WA1) 685 (WA2) & 266 \\
$\quad$ (including weight of guide shafts) (N) & & & \\
\hline
\end{tabular}

Fig. 3. Model pipe section equipped with pore pressure transducers (PPTs).

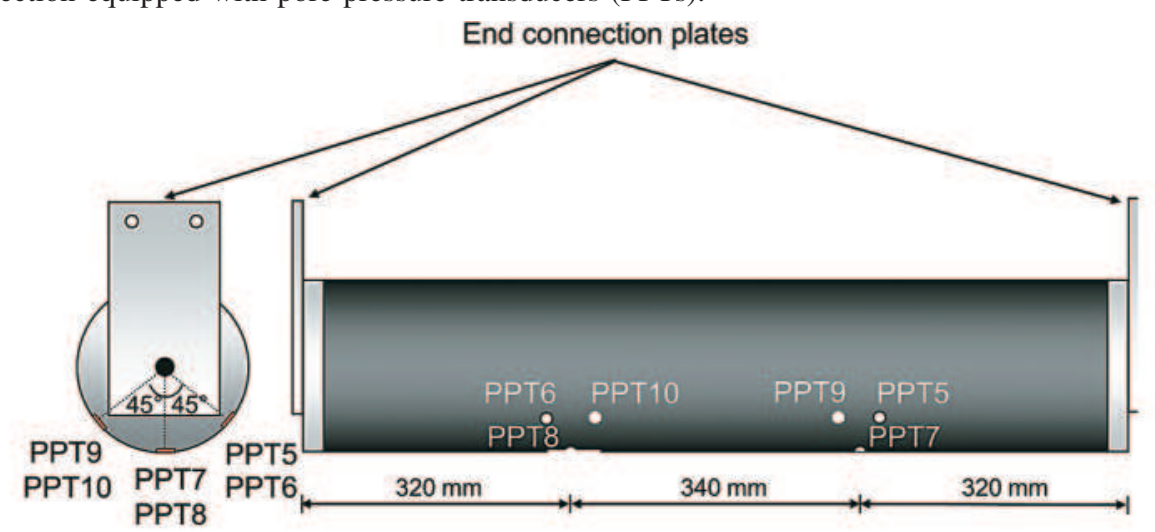

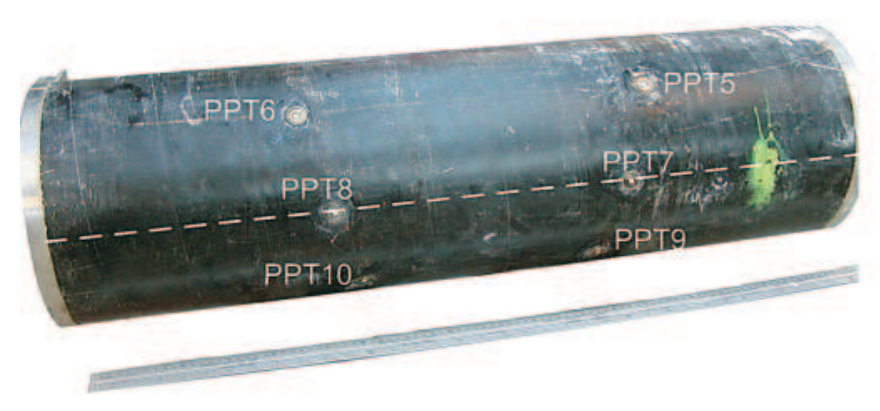

Test soils

The index properties of the E-grade kaolin clay used in this study are shown in Table 2. The West African soft clay was grab-sampled in approximately $800 \mathrm{~m}$ water depth in the Gulf of Guinea, offshore West Africa. Site investigations indicated an undrained shear strength of $\sim 1-3 \mathrm{kPa}$ in the upper $1 \mathrm{~m}$ of the seabed and an in situ moisture content in the range of $150 \%-200 \%$. The index properties of this clay are summarized in Table 2.

Laboratory tests reveal that the West African clay has a very high clay fraction $(<2 \mu \mathrm{m})$ of $80 \%$. The amount of organic matter is $7.2 \%$. The soil mineralogy comprises kaolinite $(50 \%)$, quartz (15\%), and illite (10\%), whilst smectite, chlorite, calcite, goethite, and feldspar occupy the remaining $25 \%$.

\section{Model preparation}

Each bed of soil was prepared by vacuum consolidation. Slurry with an initial water content of about $100 \%$ for the kaolin and 200\% for the West African clays was pumped into the test tank. A filter layer of geogrid and geotextile was laid onto the soil surface. This filter was cut smaller than the plan area of the tank, leaving a $100 \mathrm{~mm}$ wide border around the walls. A rubber sheet covering the entire tank area was placed on top of the filter layer. Sealing of the sys-

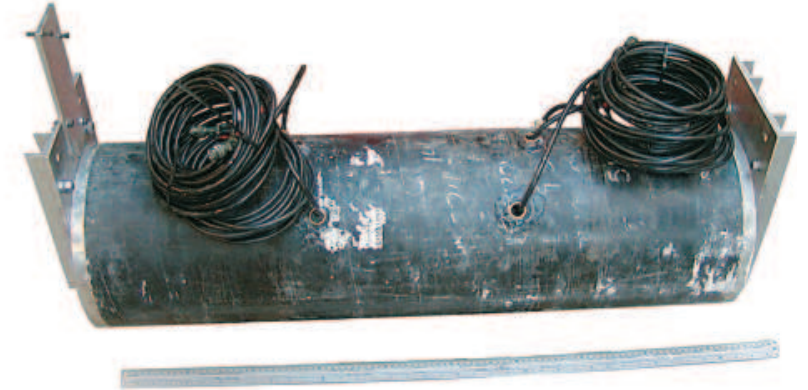

tem relied on airtight contact between the rubber sheet and the clay surface along the $100 \mathrm{~mm}$ wide strip around the tank. Negative pressure was applied using a pump capable of supplying a maximum suction pressure of $25 \mathrm{kPa}$ below atmospheric. Pore pressure transducers were embedded in the soil, which were used to monitor the progress of consolidation. Upon completion of vacuum consolidation, the depth of the soil bed was about $680 \mathrm{~mm}$ for the kaolin and $300 \mathrm{~mm}$ for the West African clay.

After each consolidation, T-bar penetration tests were carried out to characterize the shear strength profile in the soil bed. The working principle of a T-bar penetrometer is based on conversion of the measured penetration resistance to the soil undrained shear strength using the limit plasticity solutions for flow around a cylinder (Randolph and Houlsby 1984; Martin and Randolph 2006). Stewart and Randolph (1994) compared values of shear strength from various measurement methods and concluded that the T-bar penetrometer produced consistent strength values if the T-bar results were interpreted using a T-bar factor of 10.5, which is in agreement with the theoretical values deduced by Randolph and Houlsby (1984). In the present study, vane shear tests were also conducted in one of the tanks (Tank 4). The results obtained from the two methods were very similar. 
Table 2. Properties of test soils.

\begin{tabular}{lcc}
\hline & $\begin{array}{l}\text { E-grade } \\
\text { kaolin clay }\end{array}$ & $\begin{array}{l}\text { West African } \\
\text { soft clay }\end{array}$ \\
\hline Liquid limit $(\%)$ & 51 & 175 \\
Plastic limit $(\%)$ & 30 & 80 \\
In situ moisture content $(\%)$ & - & 200 \\
Soil unit weight* $\left(\mathrm{kN} / \mathrm{m}^{3}\right)$ & $\sim 16$ & 12.5 \\
Particle specific gravity, $G_{\mathrm{s}}$ & 2.61 & - \\
\hline
\end{tabular}

*For kaolin clay, this value corresponds to an undrained shear strength of $1.5 \mathrm{kPa}$; for West African clay, it is an average measured value for the strength range $1-3 \mathrm{kPa}$.

Having determined the shear strength distributions, the model pipe was placed slowly onto the model seabed. The water level during pipe placement was maintained at the soil surface to allow better positional control. The pipe weight leading to the initial pipe penetration was therefore higher than the fully submerged value corresponding to the sweeping stage, except for test WA5 in which the pipe was laid under a high water level.

\section{Test programme}

A total of five tests were carried out, two on kaolin and three on West African clay. The sequence of lateral sweeps in each test is shown in Fig. 4, and the test details are summarized in Table 3. The length of the sweeps was varied to explore the development of soil berms and the resulting lateral resistance. The lateral sweeping velocity was sufficiently high for the deformation within a sweep to be undrained.

In test WA2, vertical preloading was applied to achieve a target initial pipe embedment (prior to sweeping) of one diameter. In the other tests, the initial pipe embedment was dictated by the effective weight of the pipe and the vertical shafts, either partially or fully submerged, during pipe placement (Table 1). Although test WA2 has a higher initial embedment, which reduced the clearance to the tank bottom, comparisons between the results of tests WA1 and WA2 showed that the boundary effects due to this reduced clearance were limited. The upper bound plasticity solutions for pipe penetration described by Murff et al. (1989) provide theoretical support for this depth of sample being sufficient. Their upper bound plasticity mechanisms extend below the pipe invert by less than one-half times the pipe diameter. In the case of these experiments, the mechanism depth will be reduced further by the increase in soil strength towards the base of the tank.

The nomenclature used to describe the forces acting on the pipe, and the geometry of the pipe movement and soil erosion, is described in Fig. 5. During the initial embedment stage, the immediate embedment, $z_{\text {init }}$, from undrained deformation under the applied preload, and the total embedment at the start of the lateral test, $z_{\text {startup, }}$ are defined as vertical distances to the pipe invert relative to the original soil surface. For back-analysis of the cyclic lateral sweeps, it is necessary to consider the embedment of the pipe relative to the lower surface level, which is created when soil is scraped away into a berm. Due to the change in soil level caused by the scraping process, the pipe invert level can be described relative to the soil level ahead (denoted $z_{\text {ahead }}$ ) or behind the pipe (denoted $z_{\text {behind }}$ ) during any individual sweep. As described later, the back-analysis can be simplified by assuming that $z_{\text {behind }}$ is equal to zero, implying that there is no backwards flow or rebound of soil behind the pipe. If the soil deformation takes place at constant volume, and $z_{\text {behind }}$ is unchanged in consecutive sweeps, then the change in pipe invert level between sweeps is equal to the reduction in soil surface level.

\section{Experimental results}

\section{Shear strength profiles}

In each consolidated soil bed, at least $10 \mathrm{~T}$-bar tests covering the entire tank area were conducted using a $12 \mathrm{~mm}$ diameter T-bar penetrometer. The horizontal spatial variation was approximately $\pm 0.5 \mathrm{kPa}$. The average penetration and extraction profiles interpreted using a T-bar factor $\left(N_{\mathrm{t}}\right)$ of 10.5 are shown in Fig. 6. The marked difference between the penetration and extraction profiles indicates that the soil shear strength is sensitive to the degree of shear strain and remoulding. The West African clay exhibits a greater sensitivity than the kaolin clay. Piece-wise linear strength profiles are also plotted. These simplified profiles have been used in the interpretation of the pipeline test results.

The average surface undrained shear strength interpreted from the penetration profiles is approximately $1.3 \mathrm{kPa}$ for kaolin clay. A clear reduction in shear strength with depth can be observed in Tank 1, which results from incomplete vacuum consolidation. The presence of a stronger soil crust is more pronounced in Tank 3, which was intentionally made stronger to support a heavy pipe on the West African clay. The surface strength is about $2 \mathrm{kPa}$, which decreases to about $1.2 \mathrm{kPa}$ at a depth of $100 \mathrm{~mm}$. The soft West African clay in Tank 4 has the lowest surface strength at $0.6 \mathrm{kPa}$, which increases with depth at a gradient of $2.5 \mathrm{kPa} / \mathrm{m}$.

\section{Pipe penetration}

Placement of a pipe section onto a soil bed leads to immediate (undrained) pipe embedment, $z_{\text {init }}$. The pipe settles until the contact area provides sufficient bearing capacity. Figure 7 compares the dimensionless pipe weight, $W_{\mathrm{p}}^{\prime} / D s_{\mathrm{u}}$, and the resulting normalized pipe embedment, $z_{\text {init }} / D$.

Murff et al. (1989) present upper and lower bound plasticity solutions for a partially embedded pipe, refining the solution described by Randolph and Houlsby (1984) for flow around a cylinder. These solutions bound the relationship between pipe weight and immediate settlement, and are compared in Fig. 7 with Verley and Lund's (1995) empirical relationships, which are written as a function of the dimensionless pipe weight, $S=W_{\mathrm{p}}^{\prime} / D s_{\mathrm{u}}$, and the dimensionless soil strength, $G=s_{\mathrm{u}} / D \gamma^{\prime}$

$$
\frac{z_{\text {init }}}{D}=0.0071\left(S G^{0.3}\right)^{3.2}+0.062\left(S G^{0.3}\right)^{0.7}
$$

The pipe weight can be normalized by the undrained shear strength measured during T-bar penetration, $s_{\mathrm{u}, \text { pen }}$, or extraction, $s_{\mathrm{u}, \mathrm{ext}}$, or by some averaged value. Figure 7 shows that the best agreement between the experimental data and the theoretical solutions is found by using an operative strength equal to the geometric mean, $s_{\mathrm{u}, \mathrm{op}}=\left(s_{\mathrm{u} \text {,pen }} \times s_{\mathrm{u} \text {,ext }}\right)^{1 / 2}$. Verley and Lund's empirical solutions are best fitted using $s_{\mathrm{u} \text {,pen }}$, 
Fig. 4. Sequence of lateral sweeps in each test.

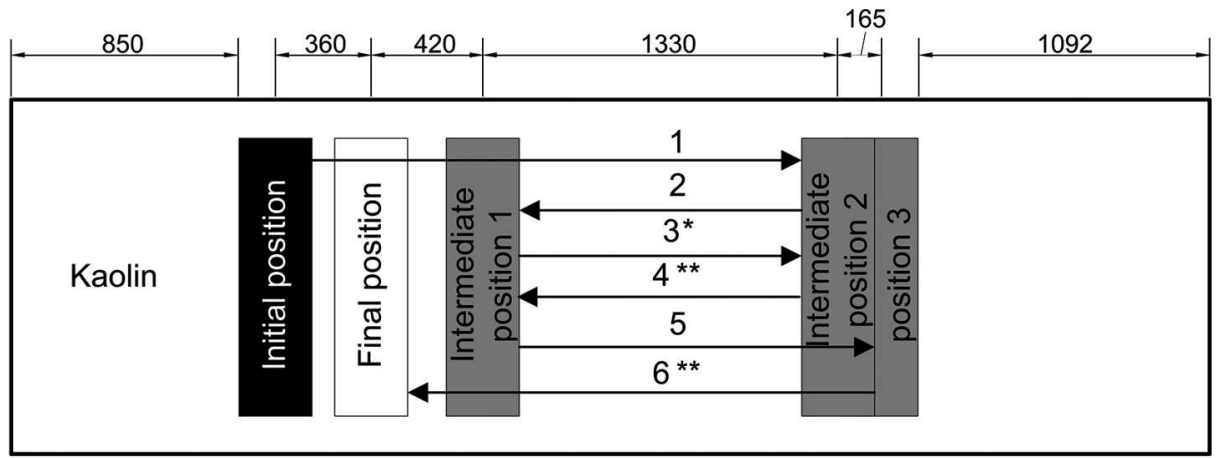

Tank 1 - Test JIP2

*4 days after previous sweep

**1 day after previous sweep

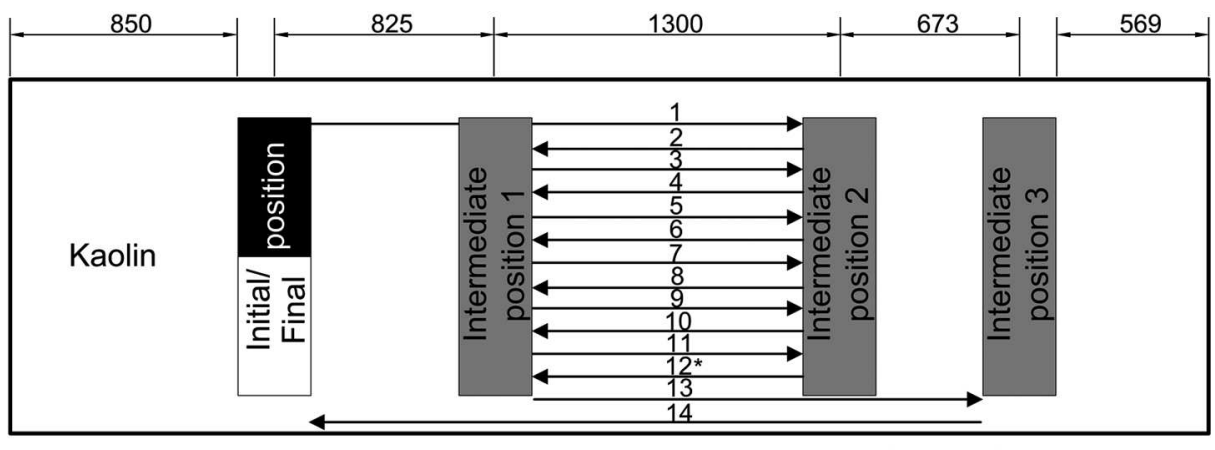

Tank 2 - Test JIP3

*2 days after previous sweep
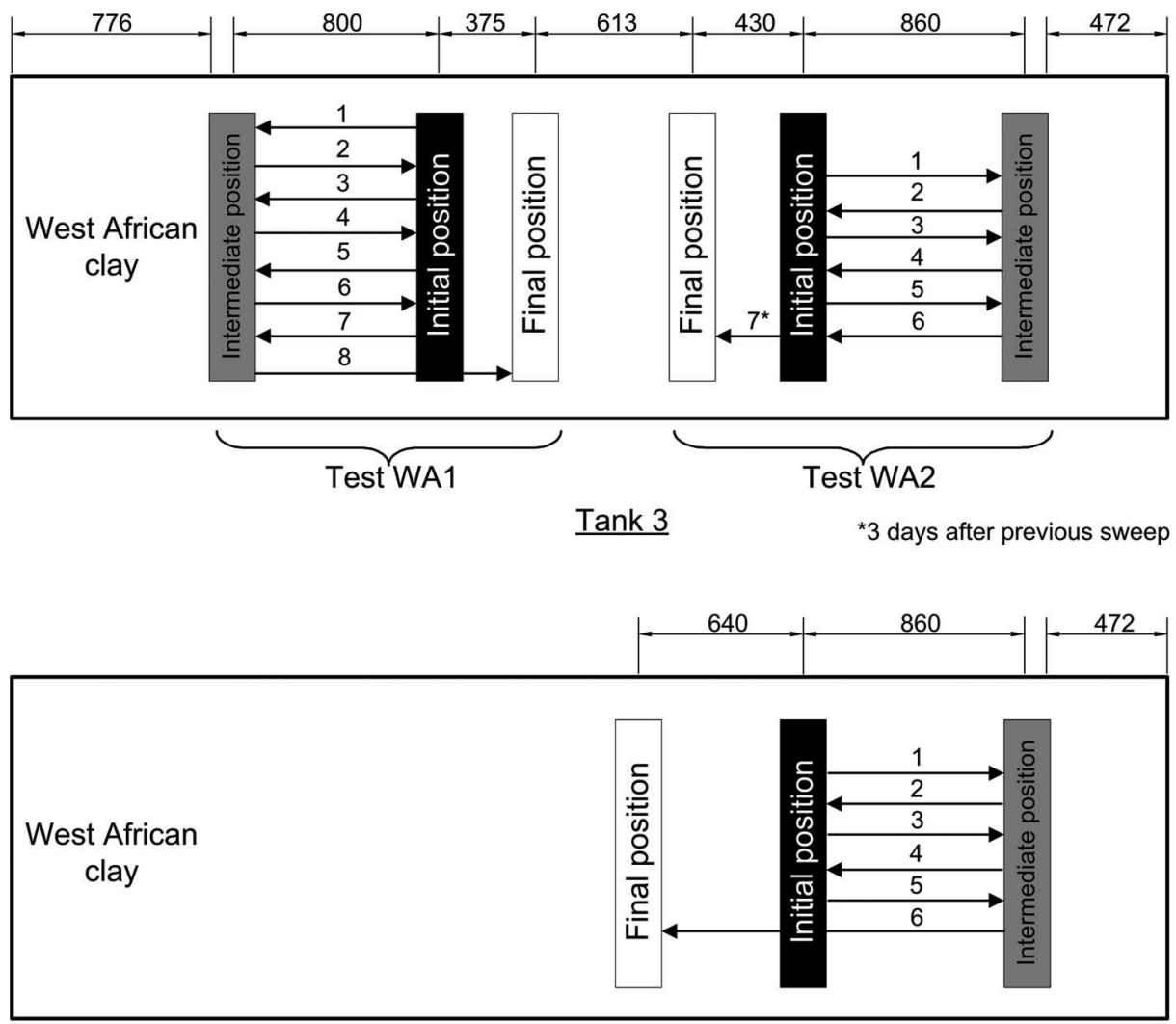
Table 3. Details of test programme.

\begin{tabular}{llllll}
\hline & JIP 2 & JIP3 & WA1 & WA2 & WA5 \\
\hline Total number of sweeps & 6 & 14 & 8 & 7 & 6 \\
Pipe diameter, $D(\mathrm{~m})$ & 0.283 & 0.283 & 0.174 & 0.174 & 0.172 \\
Pipe velocity $(\mathrm{mm} / \mathrm{s})$ & 1 & 1 & 0.5 & 0.5 & 0.5 \\
Effective pipe weight, $W_{\mathrm{p}}^{\prime}$ during placement $(\mathrm{N} / \mathrm{m})$ & 578 & 739 & 638 & 496 & 269 \\
Effective pipe weight, $W_{\mathrm{p}}^{\prime}$ during sweeping $(\mathrm{N} / \mathrm{m})$ & 651 & 336 & 692 & 692 & 269 \\
Initial pipe embedment, $z_{\text {init }} / D$ & 0.191 & 0.081 & 0.431 & 0.098 & 0.18 \\
Pipe embedment prior to first sweep, $z_{\text {startup }} / D$ & 0.318 & 0.088 & 0.557 & 0.977 & 0.186 \\
Pause period between pipe placement and sweeping $(\mathrm{h})$ & 23 & 22 & 47 & 23 & 42 \\
\hline
\end{tabular}

Fig. 5. Nomenclature for loads and geometry.

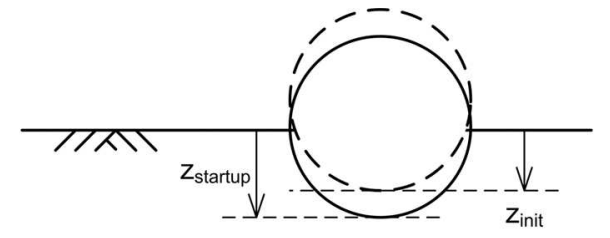

Direction of current sweep

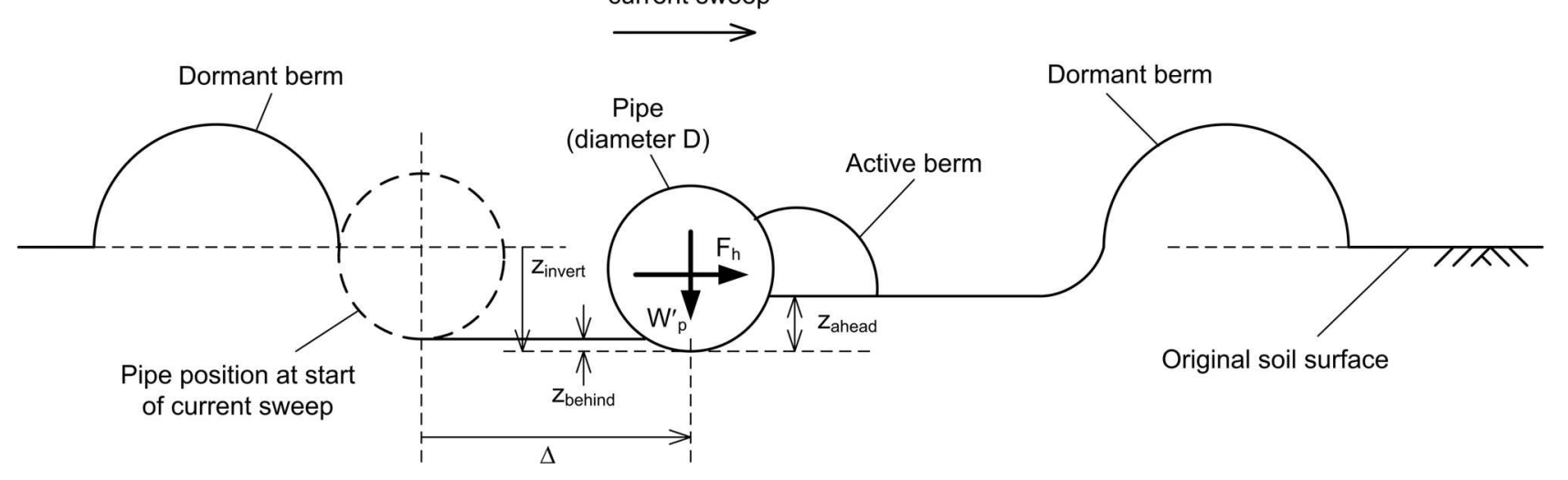

$Z_{\text {init. }}$ Immediate embedment on pipe placement

$\mathrm{z}_{\text {startup }}$ : Embedment at start of lateral sweeping which is to be expected since it is the full undrained strength that was used to calibrate this empirical expression.

Further pipe settlement occurred as a result of consolidation. The magnitude was small $(<10 \mathrm{~mm})$. Since the effective weight of the pipe led to a stress at the invert that was comparable with the preconsolidation pressure of the soil, the pipe soil was responding along a stiff reloading line. When this additional settlement was substantially complete, the actuator was connected to the pipe. The lateral sweeping began when the pipe came into equilibrium again. The pipe embedment at the start of the lateral sweeping, $z_{\text {startup }} / D$, and the time from placement to the start of sweeping are shown in Table 3.

\section{Lateral cyclic sweeping - qualitative behaviour}

Typical lateral load-displacement responses and pipe trajectories for the two different soil types are discussed in this section. Back-analysis of the measurements from all tests will be presented in the next section.

\section{Kaolin clay}

Figure $8 a$ shows the lateral soil resistance measured in kaolin test JIP3. The corresponding pipe trajectory is plotted in Fig. $8 b$. In each sweep, breakout of the pipe is followed by a sharp drop in resistance, irrespective of the sweeping direction. This brittle behaviour is due to tensile failure between the pipe and the soil behind it. This tension is initially sustained by negative excess pore pressure. Figure 9 shows the excess pore-water pressure measured at PPT9, which faces the sweeping direction in rightward sweeps. Figure $9 a$ illustrates that positive excess pore pressure is generated when the pipe is swept from the left to the right as the pipe is pushed onto the active berm in front of it. On reversal (Fig. 9b), negative excess pore pressure is generated, but quickly lost when the pipe separates from the berm created during the previous sweep. The pore pressure at PPT9 then returns back to hydrostatic conditions. It is the loss of suction caused by the formation of a gap at the soil-pipe interface that causes a sudden drop in the lateral resistance.

For all rightward sweeps, the lateral resistance gradually increases at large pipe displacements. This behaviour is caused by growth of the active berm in front of the laterally moving pipe. When the pipe approaches a soil berm that was left after a previous sweep, a sharper increase in lateral soil resistance is observed. In contrast, for leftward sweeps, the resistance at large displacements decreases gradually until a previous berm is encountered. This reduction was found 
Fig. 6. Undrained shear strength profiles: (a) kaolin clay; and (b) West African clay.
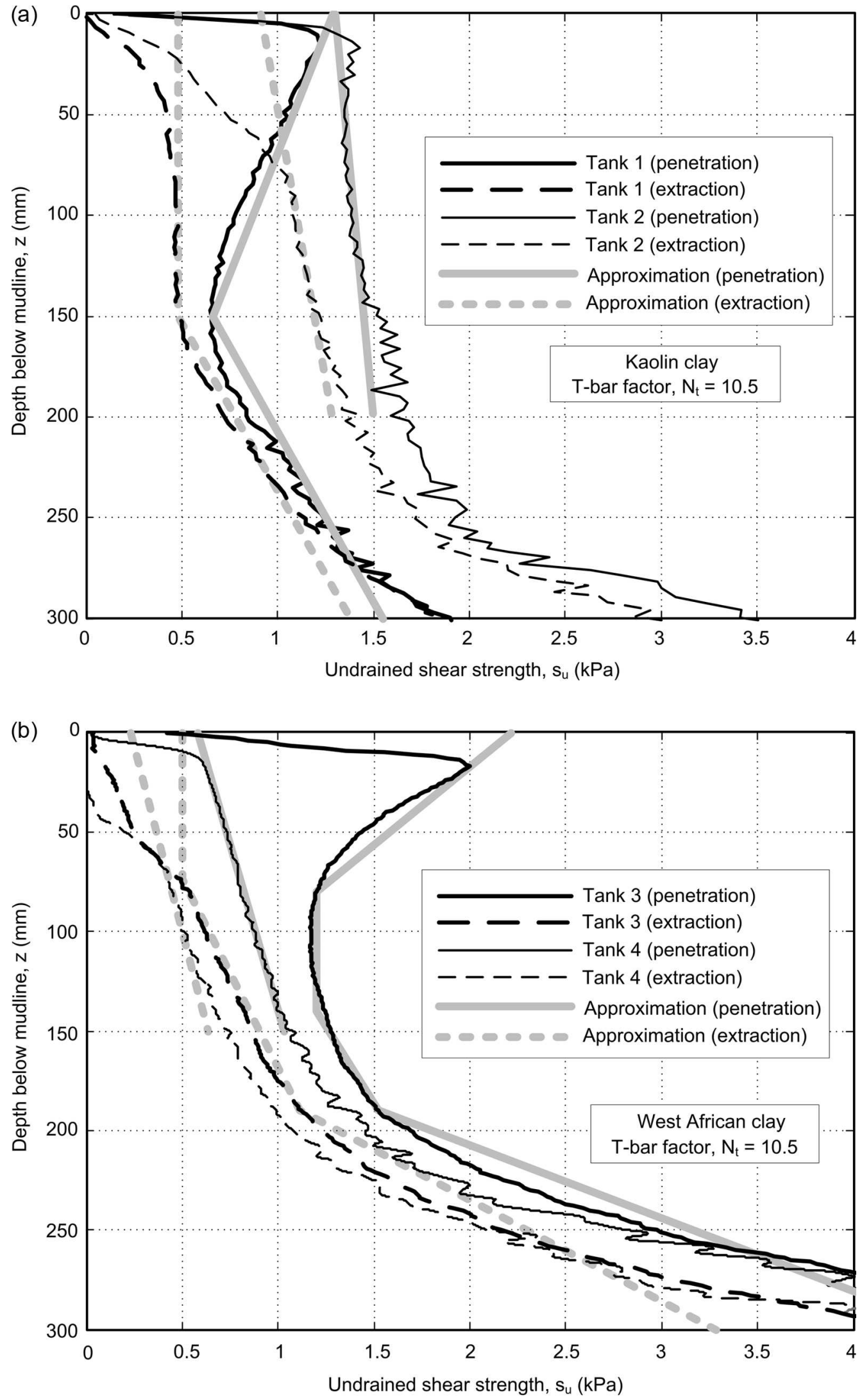
Fig. 7. Measured and predicted values of vertical pipe penetration. LB, UB, lower and upper bounds, respectively.

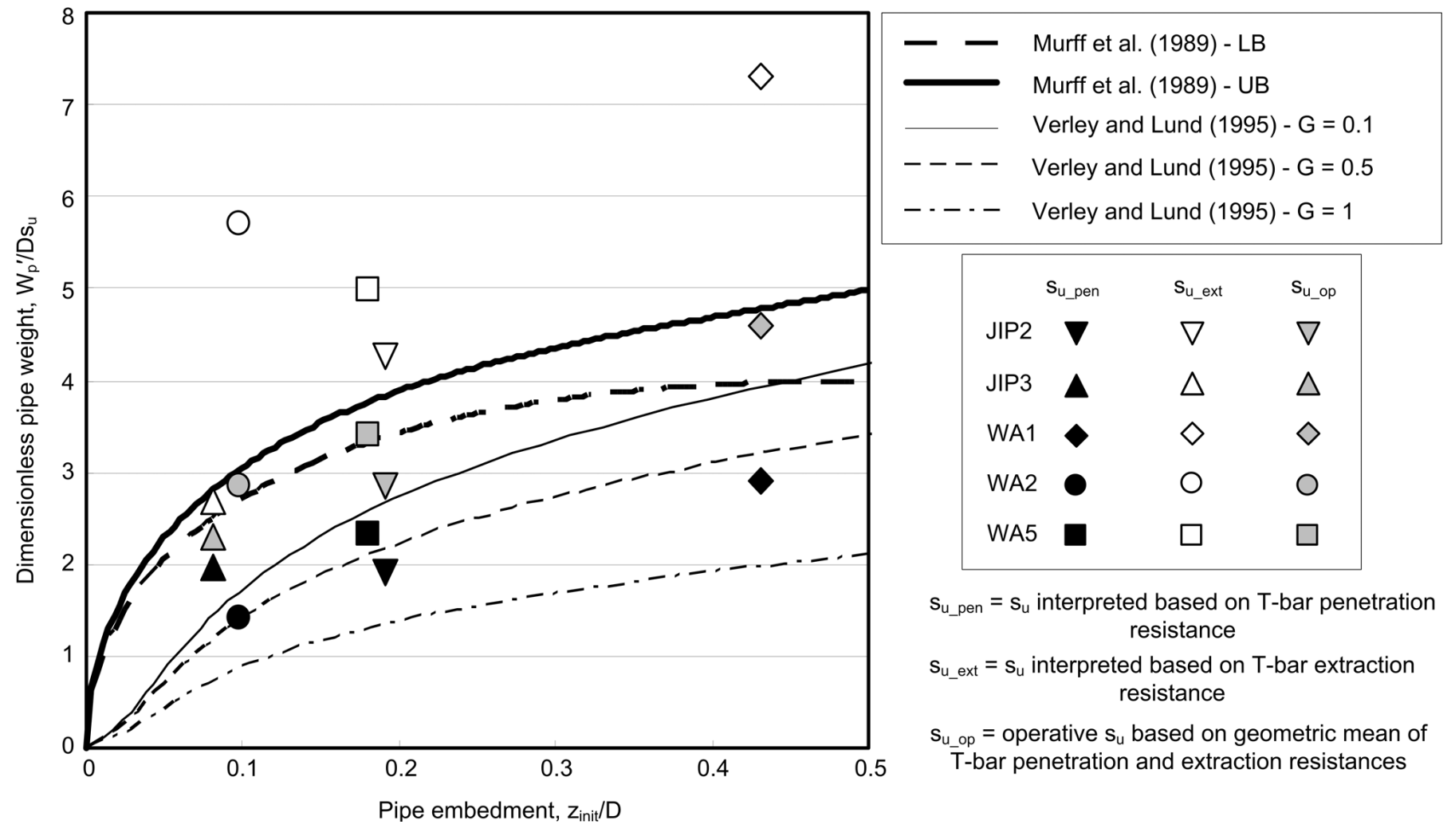

to be caused by friction in the vertical sliding rods, which changed the effective weight of the model pipe.

Overall, a repeatable load-displacement response is observed in each sweeping cycle except for the first sweep, which has significantly higher lateral resistance, both at peak and at large displacements. This higher resistance is caused by the initial pipe embedment. At the start of the first sweep, the pipe lies below the soil surface. At the start of later sweeps, the soil level is comparable to the pipe invert level, having been scraped away in the previous sweep (i.e., $z_{\text {behind }}$ during the previous sweeps was small). In the final sweeping cycle, the pipe was pushed through the dormant berms and significantly higher resistance was recorded.

The associated vertical movement of the pipe shown in Fig. $8 b$ indicates that the pipe settles in all rightward sweeps except for the first one. The amount of incremental downward movement in each cycle ranges from $0.04 D$ to $0.05 D$, which is less than the initial pipe embedment of $0.08 D$. The lack of vertical pipe movement in the leftward sweeps confirms that the effective pipe weight was reduced by friction on the sliding rods.

Very similar behaviour was observed in test JIP2, which was also carried out in kaolin. The entire set of results is not presented here, but the key values are included in the interpretation described later in this paper.

\section{West African clay}

For the three tests conducted on the West African clay, the actuator was modified to eliminate friction within the vertical guides. The results of test WA1, which are typical of these tests, are plotted in Fig. 10.
Test WA1 involved four cycles of sweeping among fixed displacement limits followed by a final sweep through the accumulated soil berm. The load-displacement response is similar to that observed in the kaolin tests. The peak breakout resistance is followed by a sudden drop due to suction release and a steady increase in lateral resistance as the active berm grows. This behaviour is observed in both rightward and leftward sweeps, confirming that asymmetry of the earlier tests was due to the original actuator design. All of the sweeps finished with a sharp increase in lateral resistance as the dormant berm was collected.

The improvement of the actuator is also demonstrated by the symmetrical pipe trajectories shown in Fig. 10b. Test WA1 has a relatively high initial pipe embedment of $0.55 D$. The increase in pipe embedment per sweep reduces as the pipe reaches deeper, stronger soil at depths greater than 100 mm (Fig. 6b).

\section{Quantitative interpretation and discussion}

\section{Key phases}

The key stages involved in lateral sweeping of a partially embedded pipe can be identified from the results described in the previous section. The four stages are depicted in Fig. 11. Breakout is characterized by a stiff load-displacement response leading to a peak in resistance. This initial resistance at a small pipe displacement is followed by a sudden drop due to separation of the pipe from the soil behind it as indicated by pore pressure measurements. During the steady active berm growth stage, a significant portion of the soil resistance exerted on the pipe is contributed by an 
Fig. 8. Typical lateral test results in kaolin clay (test JIP3): (a) force-displacement response; and (b) pipe trajectory.
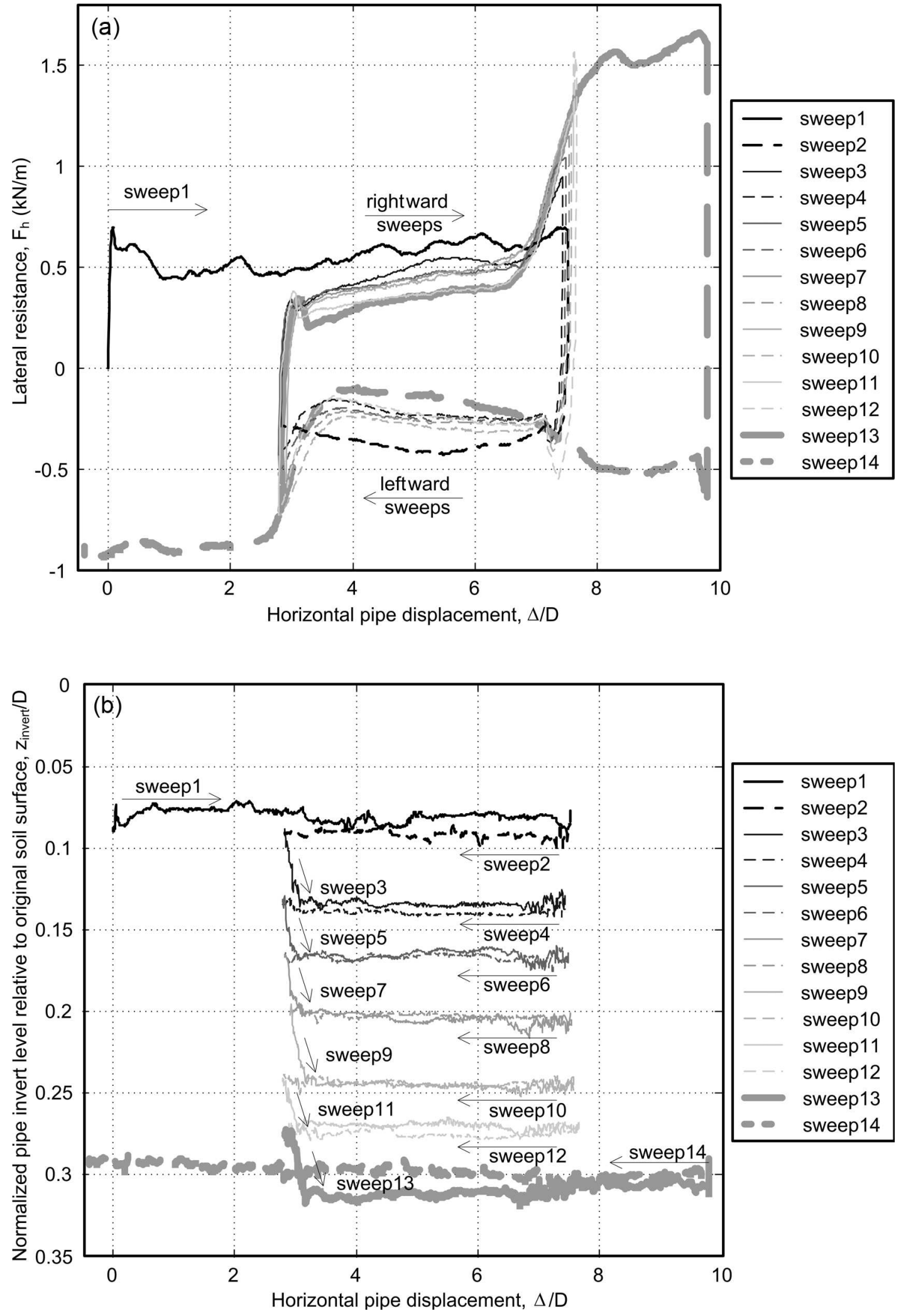

active berm formed in front of the pipe. The size of the active berm, and hence the soil resistance, is related to the lateral pipe displacement leading to a gradually increasing load-displacement response as shown in Fig. 11. As the pipe approaches a pre-existing dormant soil berm, and col- lects this material into the active berm, a steeper increase in soil resistance is experienced by the pipe.

The data collected from the five full-scale tests encompassing more than 40 sweeps are collated and compared with theoretical predictions and analyses in the following sections. 
Fig. 9. Pore pressure responses measured on the pipe (test JIP3): (a) rightward sweeps; and (b) leftward sweeps.
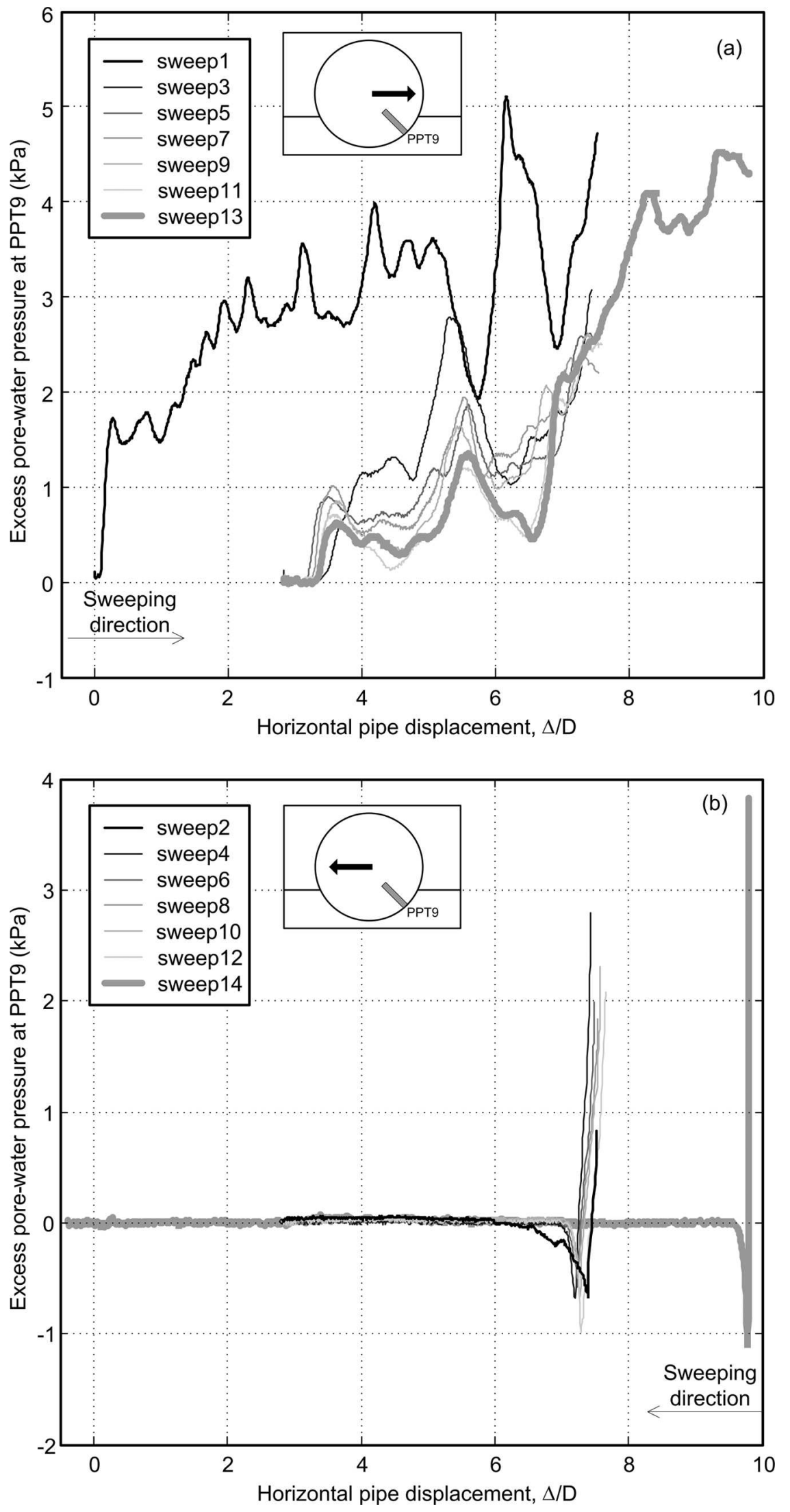
Fig. 10. Typical lateral test results in West African clay (test WA1): (a) force-displacement response; and (b) pipe trajectory.
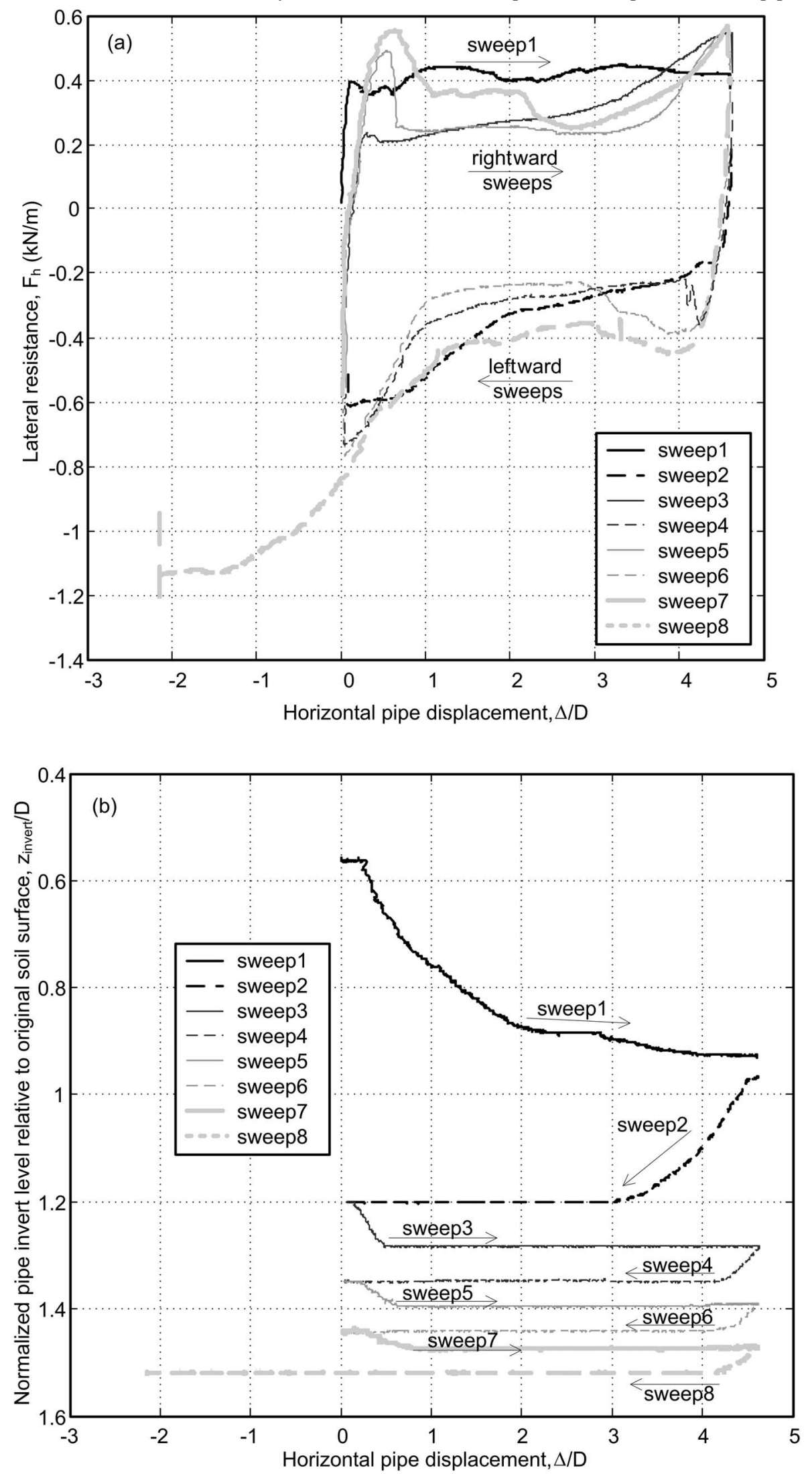
Fig. 11. Key phases during cyclic lateral sweeping of an on-bottom pipeline.

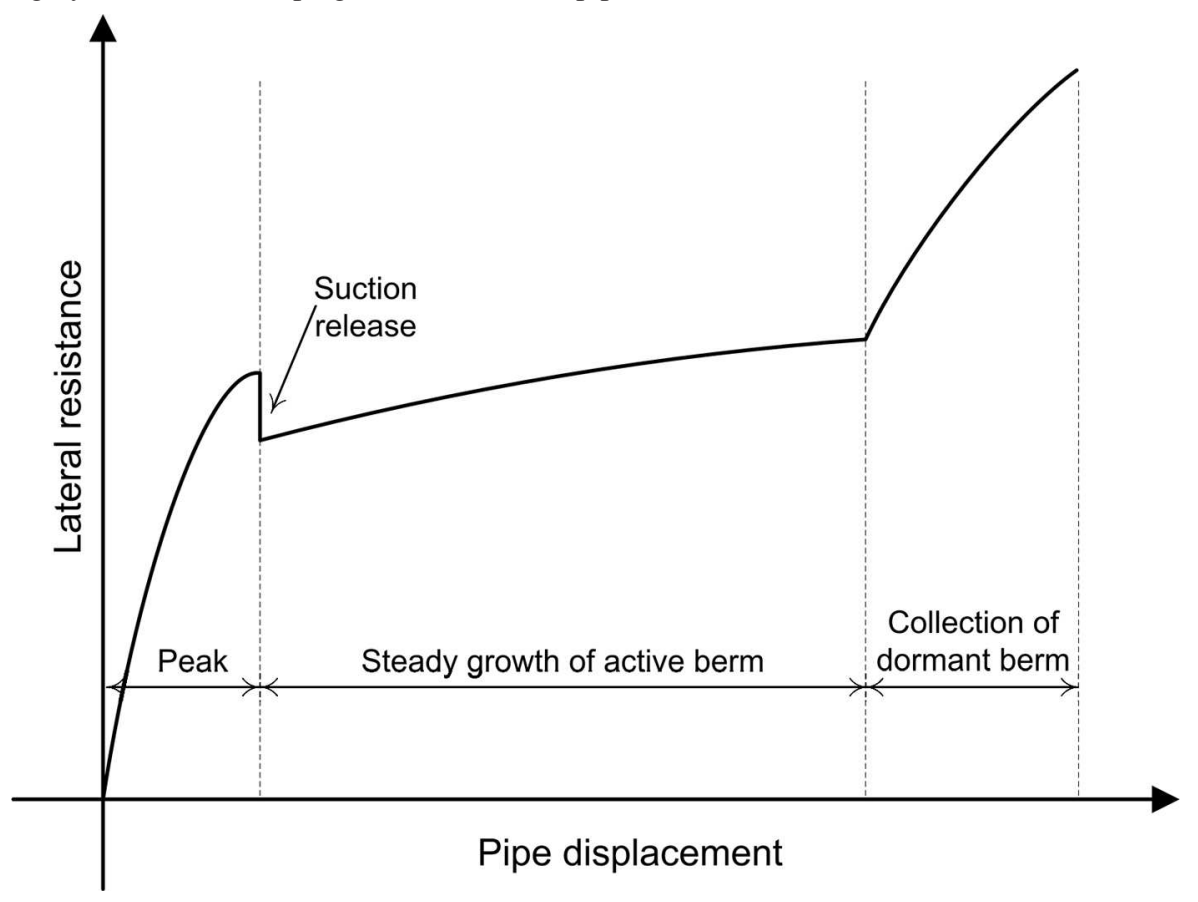

Fig. 12. Geometry of upper bound solution for lateral resistance of a partially embedded pipe: $(a)$ breakout resistance; and $(b)$ resistance during steady horizontal sweeping.
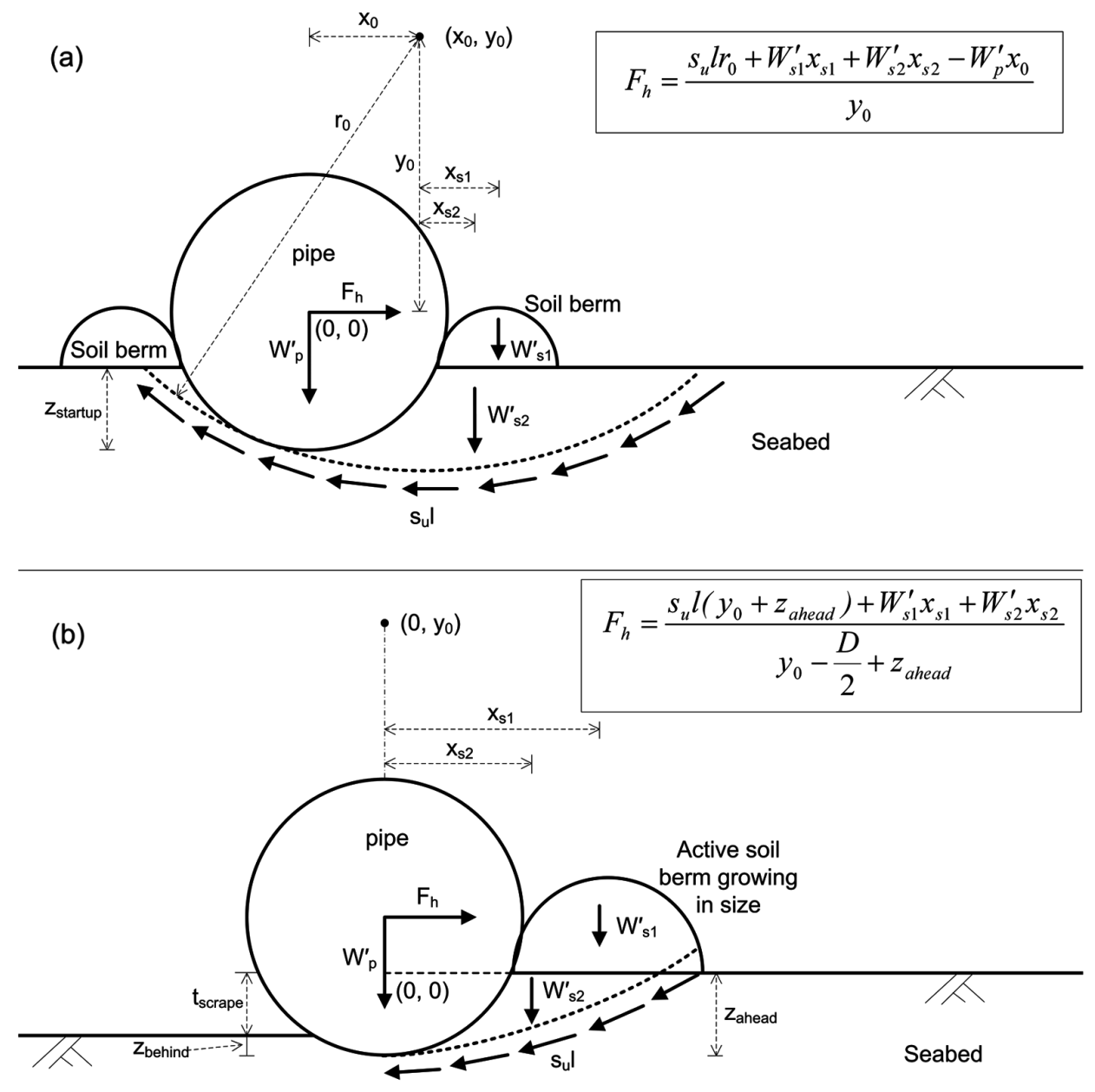
Fig. 13. Comparison of solutions for breakout resistance: (a) $G=0.67 ;(b) G=1 ;(c) G=2$; and $(d) G=\infty$.
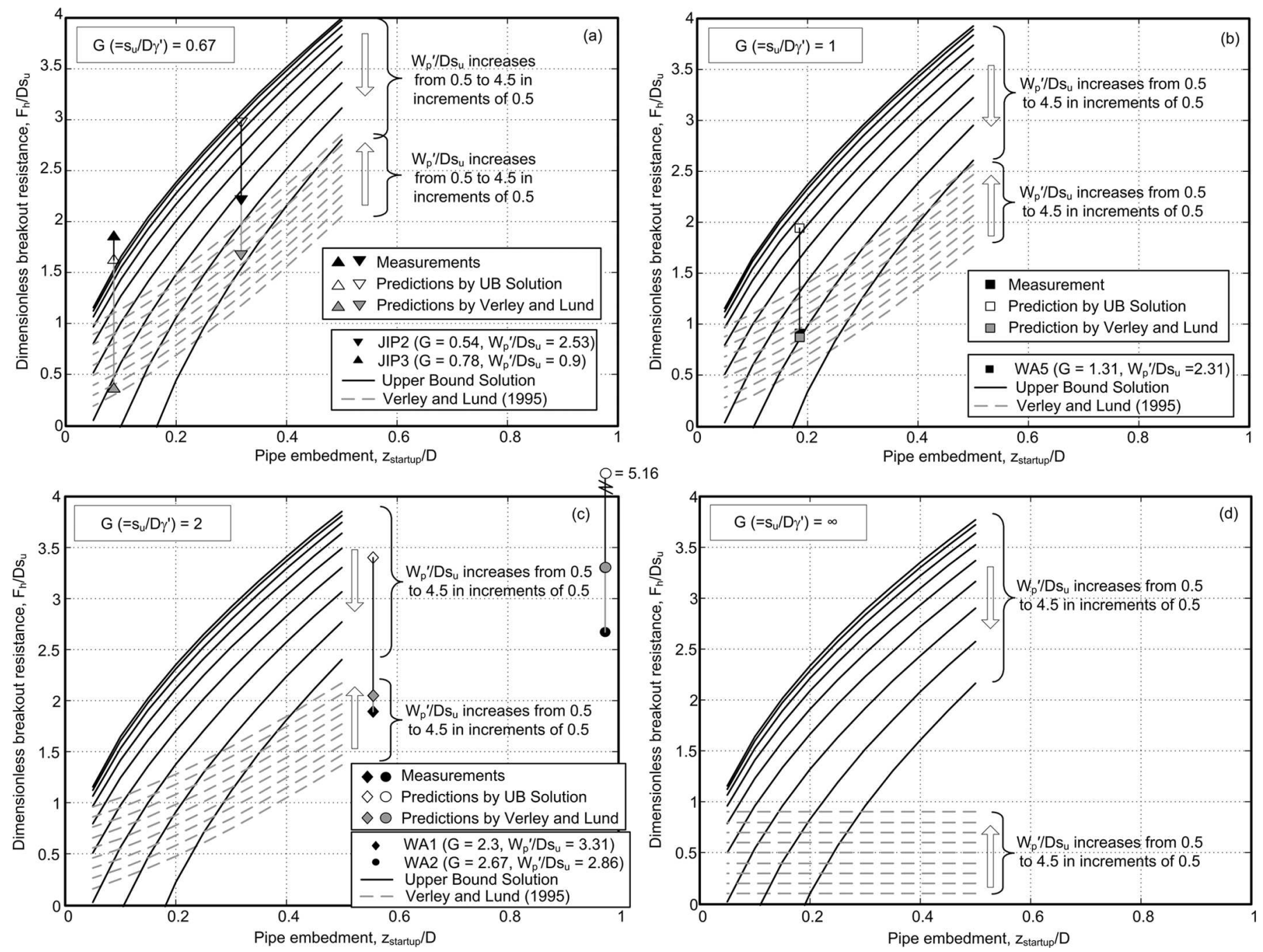

\section{Stage 1: Breakout resistance}

The prediction of breakout resistance is central to lateral buckling design. An upper bound solution is proposed in this section and compared with the experimental results. The solution, depicted in Fig. 12a, assumes that the pipe is partially embedded into a uniform strength soil bed that is characterized by an undrained shear strength, $s_{\mathrm{u}}$. The soil displaced by pipe embedment is assumed to create two semicircular soil berms whose size is dictated by the embedment and calculated assuming conservation of volume. The small region of overlap between the inner part of each berm and the pipe is ignored. The assumed failure mechanism involves a rigid soil mass failing along a circular slip surface. The horizontal force $\left(F_{\mathrm{h}}\right)$ required to displace the pipe laterally, with vertical freedom, can be found by solving the moment equilibrium equation (which is also the work equation) for a particular potential failure surface centered at $\left(x_{0}, y_{0}\right)$

[2] $\quad F_{\mathrm{h}}=\frac{s_{\mathrm{u}} l r_{0}+W_{\mathrm{s} 1}^{\prime} x_{\mathrm{s} 1}+W_{\mathrm{s} 2}^{\prime} x_{\mathrm{s} 2}-W_{\mathrm{p}}^{\prime} x_{0}}{y_{0}}$

where

$F_{\mathrm{h}}$ is the horizontal force per unit length;

$s_{\mathrm{u}}$ is the soil undrained shear strength; $l$ is the length of the slip surface;

$r_{0}$ is the radius of the slip circle;

$W_{\mathrm{s} 1}^{\prime}$ and $W_{\mathrm{s} 2}^{\prime}$ are the effective weights of the soil masses per unit length;

$x_{\mathrm{s} 1}$ and $x_{\mathrm{s} 2}$ are the moment arms of $W_{\mathrm{s} 1}^{\prime}$ and $W_{\mathrm{s} 2}^{\prime}$, respectively, and

$W_{\mathrm{p}}^{\prime}$ is the effective pipe weight per unit length.

The solution is optimized by defining a fine grid of $x_{0}$ and $y_{0}$ values, searching for the lowest $F_{\mathrm{h}}$, and refining this location to accurately determine the minimum. Further assumptions are made to facilitate the calculations. The line of action of $F_{\mathrm{h}}$ is assumed to pass through the pipe centre. In reality, the true location is variable, but must lie below the level of the soil surface. However, since $y_{0} \gg\left[(D / 2)-z_{\text {startup }}\right]$, this simplification is minor. The slip surface extends to the mudline behind the pipe, modelling full soil-pipe adhesion. This approach takes into account the suction generated at the soilpipe interface as observed in the experiments. It is also assumed that the undrained shear strength is fully mobilized along the slip surface.

Verley and Lund (1995) proposed an empirical equation for predicting breakout resistance as a function of $S\left(=W_{\mathrm{p}}^{\prime} / D s_{\mathrm{u}}\right)$ and $G\left(=s_{\mathrm{u}} / D \gamma^{\prime}\right)$, based on a database of model test results 
Fig. 14. Predictions of breakout resistance: (a) upper bound solution; and (b) Verley and Lund's (1995) empirical expression.
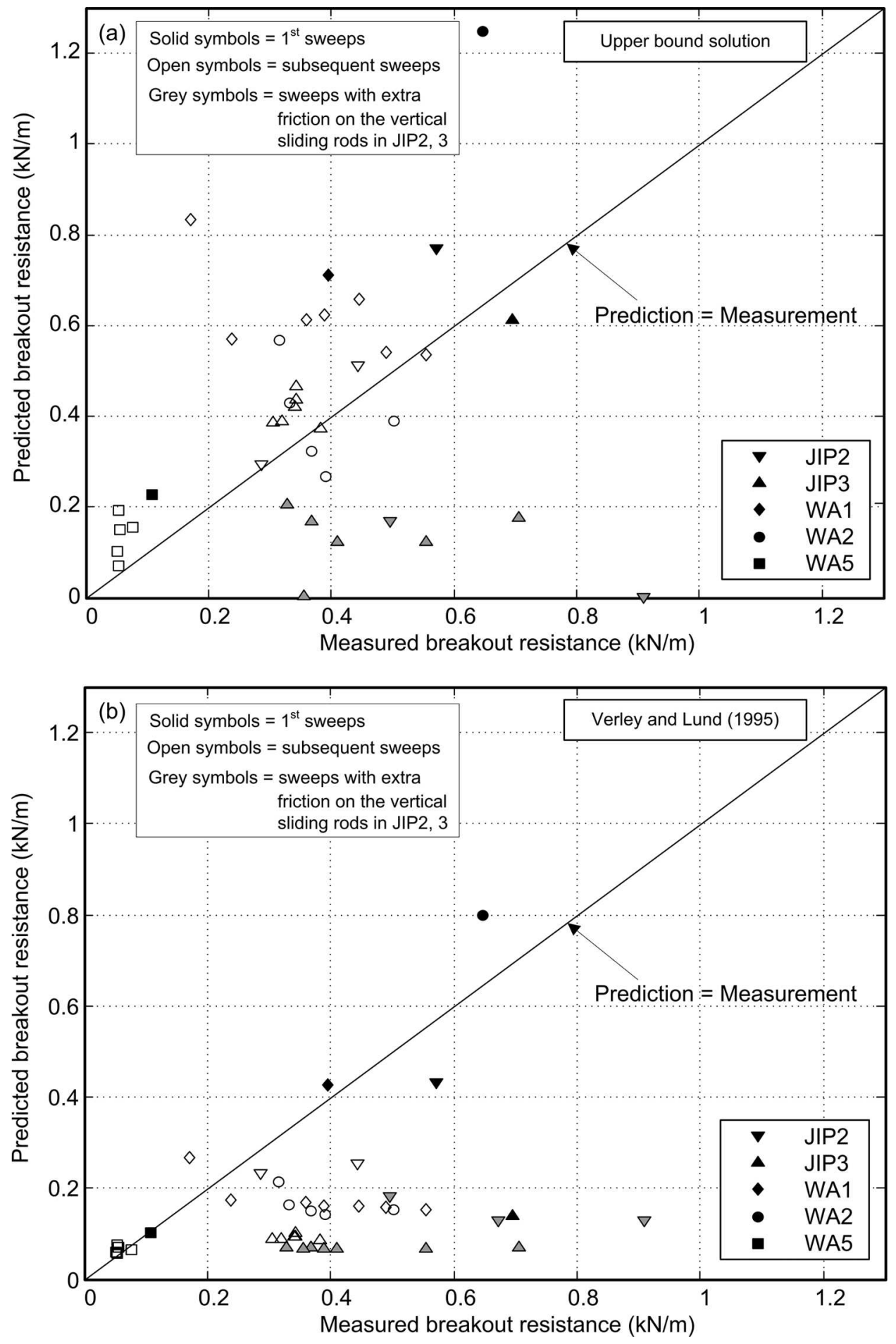

[3]

$$
\frac{F_{\mathrm{h}}}{D s_{\mathrm{u}}}=\mu S+4.13 G^{-0.392}\left(\frac{z_{\text {startup }}}{D}\right)^{1.31}
$$

where $\mu$ is a coefficient of friction for which a value of 0.2 is recommended, and $z_{\text {startup }}$ is the pipe embedment at breakout.

The calculated breakout forces for different values of $S$ and $G$ using the above two methods are plotted as a function of pipe embedment in Fig. 13. The measurements are also shown for comparison. The discrepancies between the measured and the calculated values using the two methods are represented by the lengths of the arrows. The $s_{\mathrm{u}}$ values have been taken from the approximated penetration profiles in Fig. 6 at the pipe invert level prior to sweeping (i.e., $z_{\text {startup }}$ in Table 3). Verley and Lund's solutions include a frictional term $(\mu S)$, leading to higher breakout resistance for increasing effective pipe weight. In contrast, the proposed upper bound solution predicts a lower breakout resistance for a heavier pipe at the same embedment. This 
occurs because the pipe moves downwards in the optimal upper bound solution (matching the test observations), so the pipe weight aids failure. This trend in the upper bound solution is analogous to foundation failure under combined loading, which is normally presented by an interaction diagram between vertical and horizontal load. An alternative way of presenting the solution would therefore be in $W^{\prime} / D s_{\mathrm{u}}$ versus $F_{\mathrm{h}} / D s_{\mathrm{u}}$ space. The parameter $G$ has minimal influence on the upper bound solution, but it has a significant effect on the breakout resistance predicted by Verley and Lund's method.

To directly assess the performance of the two methods, the measured breakout resistances are plotted against predictions in Fig. 14. This figure also includes the breakout resistance measured in subsequent sweeps for which the $s_{\mathrm{u}}$ values have been taken as the approximated penetration strengths (Fig. 6) at the pipe invert level at the start of the sweep. Although the data are scattered, the points with the largest discrepancies compared to predictions from the upper bound solution are those from JIP2 and JIP3 in which the extra friction on the sliding rods changed the effective pipe weight. If these points are ignored, the upper bound solution provides better predictions of these test results than Verley and Lund's equation, and has the benefit of a rational basis.

\section{Stage 2: Steady growth of active berm}

The force-displacement responses in the first, third, and fifth sweeps are extracted and plotted in a dimensionless form in Fig. 15. Figures 8 and 10 show that the pipe settles after breakout and it then sweeps at a constant elevation. The $s_{\mathrm{u}}$ values for normalization of the load during stage 2 have therefore been taken as the approximated penetration strengths (Fig. 6) at the deepest embedment during each sweep. Figure 15 shows that the soil strength ratio, $G$, affects the normalized lateral resistance during the state of steady growth of active berm. A small $G$ value implies soil that is heavy but weak, which therefore increases the normalized resistance required to lift material into the active berm ahead of the pipe. The trend is not as distinct in Fig. $15 a$ for first sweeps. This is presumably because the size of the active berm formed during initial penetration controls the lateral resistance in the first sweep.

The upper bound solution described in the previous section can be modified to capture the behaviour observed during steady growth of the active berm, with the pipe moving horizontally. As shown in Fig. 12b, the volume of soil scraped by a pipe at a particular embedment moving laterally through displacement, $\Delta$, can be assumed to have transformed to an active soil berm sitting in front of the pipe. This allows the lateral resistance to be predicted as a function of the scrape depth, $t_{\text {scrape }}=z_{\text {ahead }}-z_{\text {behind }}$, and the pipe displacement $(\Delta)$. The centre of rotation must lie directly above the pipe centre when the pipe is moving horizontally. Deformation of the soil within the berm is ignored, but in reality some shearing is necessary in order for the berm to remain the same shape as it grows.

Solutions for different pipe embedments and different $G$ values are plotted in Fig. 16 as a function of pipe displacement. These solutions demonstrate that the dependency of lateral resistance on $G$ changes with pipe embedment. At
Fig. 15. Lateral resistance at steady accretion state: (a) first sweeps; (b) third sweeps; and (c) fifth sweeps.
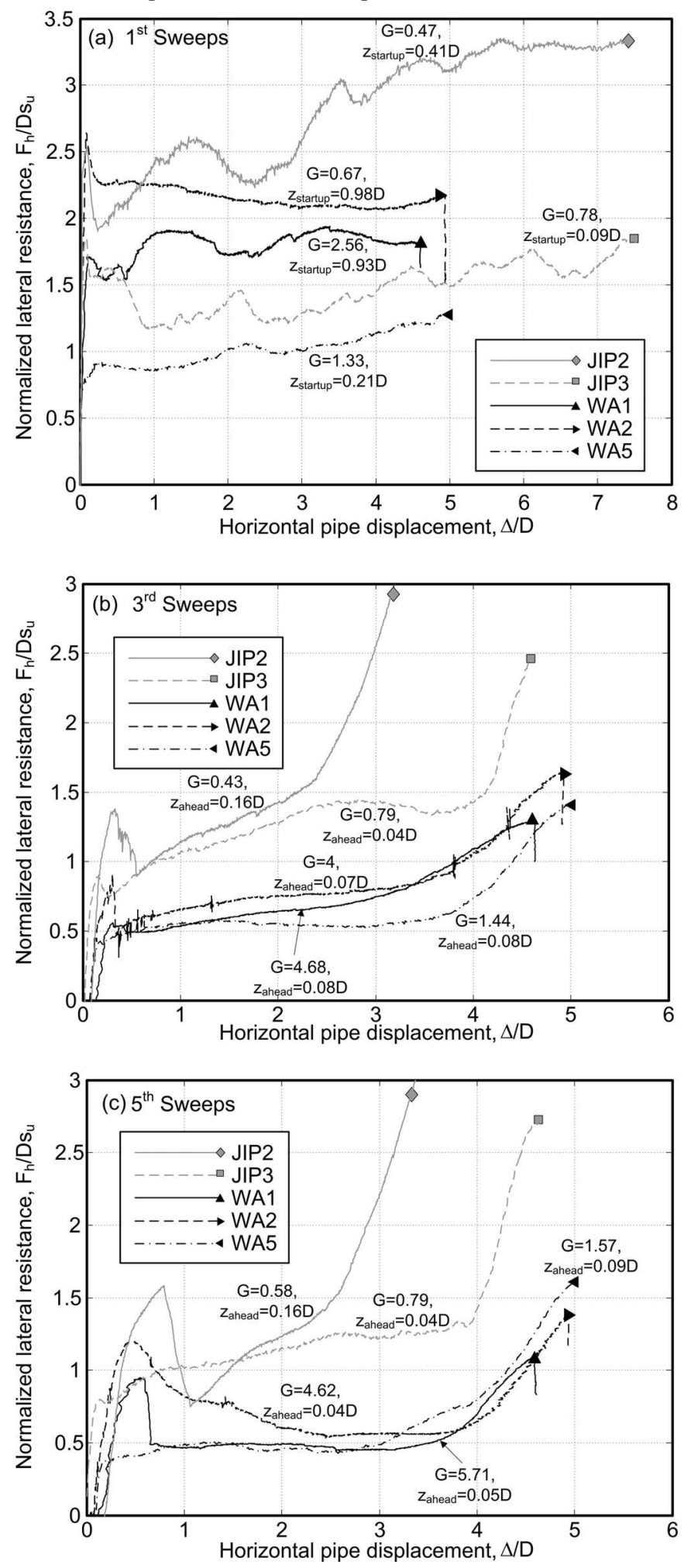

low embedment, the size of the active berm is relatively small, and the resistance arises primarily from shearing the soil. The soil weight therefore has less influence on the resulting lateral resistance, and vice versa. 
Fig. 16. Upper bound solution for lateral resistance during steady growth of an active berm.

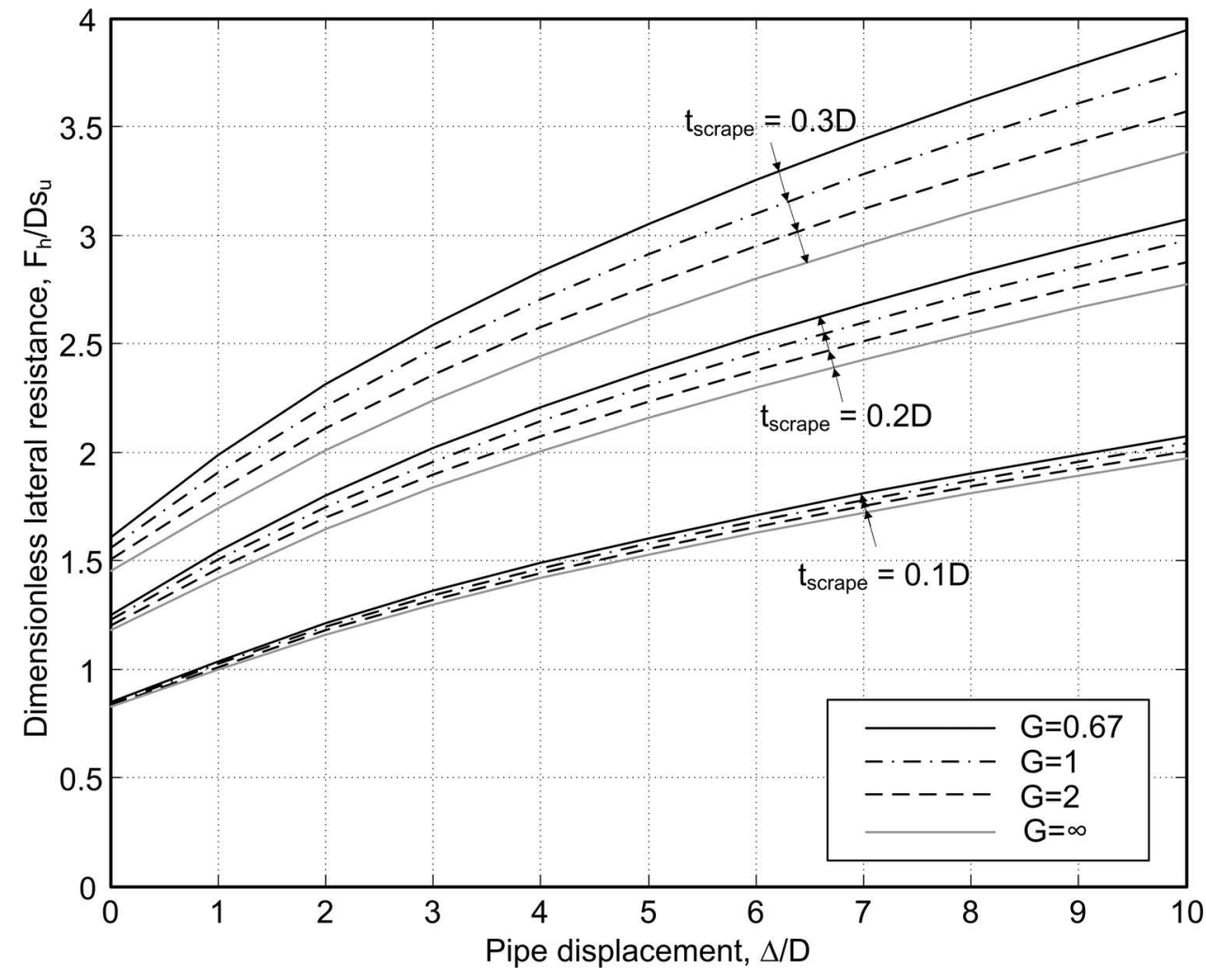

\section{Lateral resistance after collection of a dormant berm}

The modified upper bound solution shown in Fig. $12 b$ can also be used to back-analyse the measured resistance at the end of each sweep when the dormant berm is collected. The size of a dormant berm depends on the history of the pipe movement. If the soil deformation is at constant volume, then the dormant berm volume equals the volume of soil scraped in that direction, until the berm is large enough to topple over the pipe. Based on this assumption, the predicted berm resistances at the end of each sweep - assuming collection of the entire dormant berm - have been calculated and compared with the measurements in Fig. 17. As for stage 2, the $s_{\mathrm{u}}$ values for normalization of the load during stage 3 have been taken as the approximated penetration strength (Fig. 6) at the deepest embedment that the pipe reaches in that sweep.

During the early sweeps, the resistance is well predicted. However, the resistance at the end of the later, deeper sweeps, is overpredicted. This is primarily because the dormant berm was not fully mobilized during these sweeps, which took place between fixed displacement limits. Inspection of Fig. 10a shows that in later sweeps, the lateral resistance is still rising steeply at the end of each sweep. If the pipe had been pushed fully through the dormant berm, better agreement with the upper bound solution would be observed. The degree of partial mobilization in the later sweeps is indicated by the extrapolated values in Fig. $17 b$. The extrapolated berm resistances are calculated based on the rate of increase in lateral resistance at the end of the sweep, extended by a further $0.5 \mathrm{D}$. These extrapolated values show a consistent trend, independent of depth. Addi- tional mechanisms that may contribute to the lower observed resistance are that $(i)$ the soil has softened due to remoulding within the berm and swelling of the bed after material was scraped away in earlier sweeps, and (ii) for very large berms, the soil can fall over the crown of the pipe. This second effect was observed in the final sweeps of tests WA1 and WA2.

This simple upper bound solution provides a reasonable basis for estimating the soil resistance at different stages of large-amplitude cyclic lateral pipeline movement.

\section{Conclusions}

The lateral force exerted on a partially embedded pipe during large amplitude cyclic movement has been examined in model tests conducted at full-scale. Tests were conducted on kaolin clay and a high plasticity soft clay from offshore West Africa. Four key stages in the force-displacement response have been identified: (i) breakout, (ii) suction release, (iii) steady berm growth, and (iv) dormant berm collection. A peak value of resistance was observed at breakout, followed by a sudden drop due to tensile failure linked to a loss of suction as the pipe separated from the soil behind it. Thereafter, the lateral resistance increased gradually due to the growth of an active berm as the pipe scraped away a thin layer of soil. During repeated cycles, additional resistance was encountered whenever a dormant berm left by a previous sweep was collected and accumulated into the active berm.

An upper bound solution has been proposed for the prediction of the resistance at breakout, steady active berm growth, and dormant berm collection. Good agreement was observed 
Fig. 17. Prediction of berm resistance by upper bound solution: (a) predictions compared to measurements; and $(b)$ influence of pipe embedment on predictions.
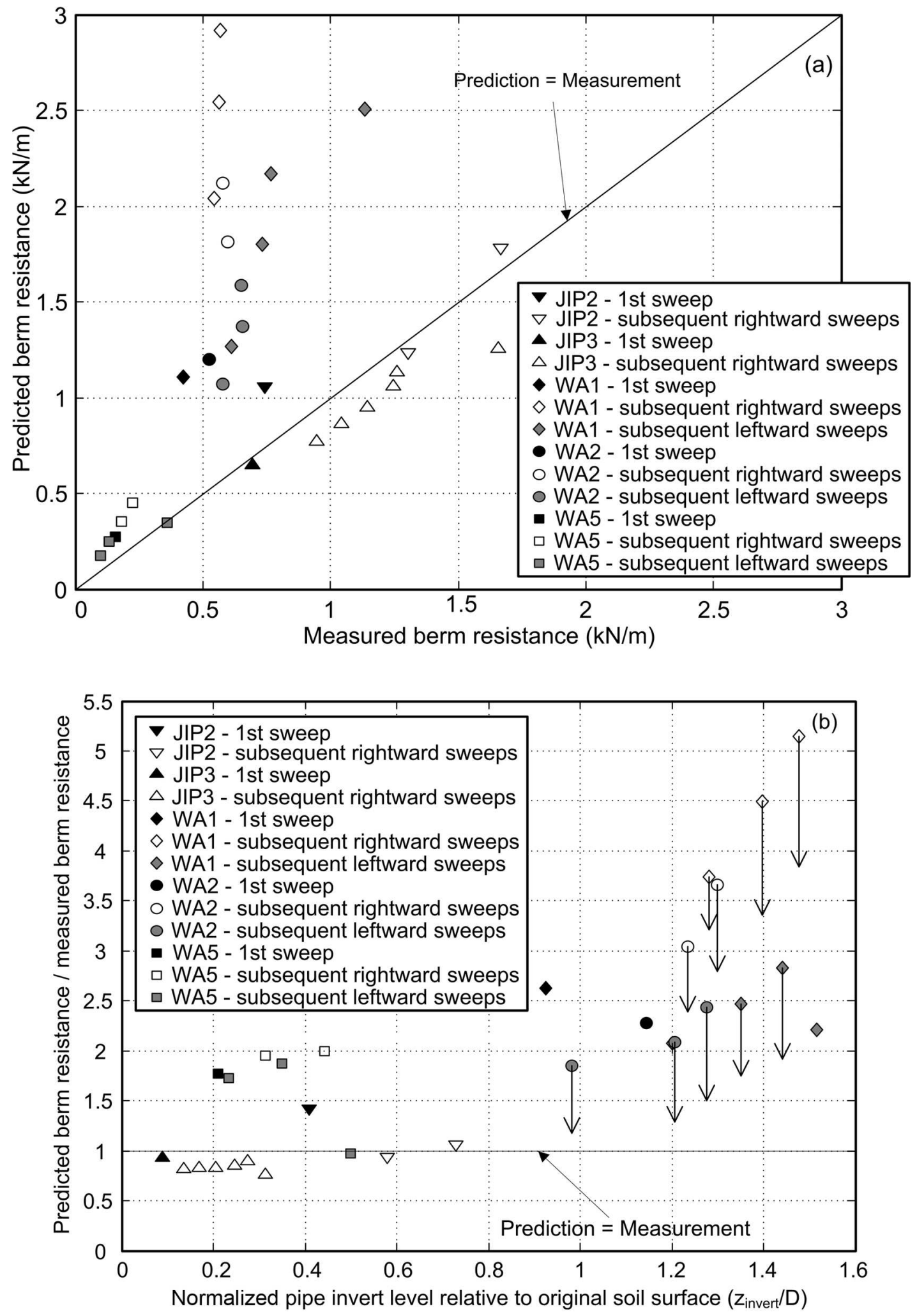

between measurements and predictions of breakout resistance, and the solution has a better physical basis than existing empirical methods. The solution uses conservation of volume to capture the increasing resistance during large-amplitude movements as an active soil berm grows and the hardening response when a dormant berm is collected. Less satisfactory correlation was obtained between the measurements and predictions of dormant berm resistance. This is because 
the cyclic sweeps were of controlled amplitude, and the berm resistance was not fully mobilized at the end of each sweep. Figures $15 b$ and $15 c$ show that the lateral resistance was rising at the end of each sweep, confirming that the berm resistance was only partially mobilized in each case.

\section{Acknowledgements}

This work was funded by Phase I of the SAFEBUCK Joint Industry Project, which focussed on the development of guidelines for the safe design of offshore pipelines using lateral buckling. SAFEBUCK is coordinated by Boreas Consultants Ltd., and the Participants in Phase I were BP, ConocoPhillips, ExxonMobil, Petrobras, and Shell, as well as the US Government through the Minerals Management Service (MMS). The authors acknowledge the technical advice related to lateral buckling and soil-pipe interaction provided by David Bruton of Boreas Consultants Ltd.

\section{References}

AGA. 1998. Submarine pipeline on-bottom stability analysis and design considerations. PR-178-9731, American Gas Association, Washington, DC.

Brennodden, H., Sveggen, O., Wagner, D.A., and Murff, J.D. 1986. Full-scale pipe-soil interaction tests. In Proceedings of the 18th Offshore Technology Conference, Houston, Tex., 5-8 May 1986. OTC 5338, pp. 433-440.

Harrison, G.E., Brunner, M.S., and Bruton, D.A.S. 2003. King flowlines - thermal expansion design and implementation. In Proceedings of the 35th Offshore Technology Conference, Houston, Tex., 5-8 May 2003. OTC 15310, pp. 1-11.

Kaye, D., Marchand, D., Blondin, P., and Carr, M. 1995. Lateral buckling design of the Dunbar - North Alwyn double wall insulated pipeline. In Proceedings of the 9th Offshore Pipeline Technology Conference, Copenhagen.

Lyons, C.G. 1973. Soil resistance to lateral sliding of marine pipelines. In Proceedings of the 5th Offshore Technology Conference, Houston, Tex., 29 April - 2 May 1973. OTC 1876, pp. 479-484.

Martin, C.M., and Randolph, M.F. 2006. Upper-bound analysis of lateral pile capacity in cohesion soil. Géotechnique, 56: 141-145.

McKinnon, C., Mansour, M., and Gibbons, N. 2001. Erskine replacement pipeline project - design challenges. In Proceedings of the 24th Offshore Pipeline Technology Conference, Amsterdam, 26-27 February 2001.

Murff, J.D., Wagner, D.A., and Randolph, M.F. 1989. Pipe penetration in cohesive soil. Géotechnique, 39: 213-229.

Nystrom, P.R., Tornes, K., Karlsen, J.S., Endal, G., and Levold, E. 2002. Design for thermal buckling of Asgard transport gas trunkline. International Journal of Offshore and Polar Engineering, 12: 271-279.

Pasqualino, L.P., Alves, J.L.D., and Battista, R.C. 2001. Failure simulation of a buried pipeline under thermal loading. In Proceedings of the 20th International Conference on Offshore Mechanics and Arctic Engineering (OMAE), Rio De Janiro, Brazil, 3-8 June 2001.OMAE2001/PIPE-4124.

Perinet, D., and Frazer, I. 2006. Mitigation methods for deepwater pipeline instability induced by pressure and temperature varia- tions. In Proceedings of the Offshore Technology Conference 2006, Houston, Tex., 1-4 May 2006. OTC17915.

Randolph, M.F., and Houlsby, G.T. 1984. The limiting pressure on a circular pile loaded laterally in cohesive soil. Géotechnique, 34: 613-623.

Schotman, G.J.M., and Stork, F.G. 1987. Pipe-soil interaction: a model for laterally loaded pipelines in clay. In Proceedings of the 19th Offshore Technology Conference, Houston, Tex., 2730 April 1987. OTC 5588.

Stewart, D.P., and Randolph, M.F. 1994. T-bar penetration testing in soft clay. Journal of Geotechnical Engineering, 120: 22302235. doi:10.1061/(ASCE)0733-9410(1994)120:12(2230).

Verley, R., and Lund, K.M. 1995. A soil resistance model for pipelines placed on clay soils. In Proceedings of the 14th International Conference on Offshore Mechanics and Arctic Engineering (OMAE), Copenhagen, Denmark, 19-22 June 1995. Vol 5, pp. 225-232.

Wagner, D.A., Murff, J.D., Brennodden, H., and Sveggen, O. 1989. Pipe-soil interaction model. Journal of Waterway, Port, Coastal, and Ocean Engineering, 115: 205-220.

Zhang, G., Stewart, D.P., and Randolph, M.F. 2002. Kinematic hardening model for pipeline-soil interaction under various loading conditions. International Journal of Geomechanics, 2: 419-446. doi:10.1061/(ASCE)1532-3641(2002)2:4(419).

\section{List of symbols}

$D$ pipe diameter

$F_{\mathrm{h}}$ horizontal soil resistance (force) per unit length

$G$ dimensionless group, $s_{\mathrm{u}} / D \gamma^{\prime}$

$G_{\mathrm{s}}$ average specific gravity of soil particles

$l$ length of slip surface in the upper bound solution

$N_{\mathrm{t}}$ T-bar factor

$r_{0}$ radius of a slip circle in the upper bound solution

$S$ dimensionless group, $W_{\mathrm{p}}^{\prime} / D \mathrm{~s}_{\mathrm{u}}$

$s_{\mathrm{u}}$ undrained shear strength of soil

$s_{\mathrm{u}, \mathrm{ext}}$ undrained shear strength of soil measured by extraction of a T-bar test

$s_{\mathrm{u}, \mathrm{op}}$ operative undrained shear strength of soil

$s_{\mathrm{u}, \text { pen }}$ undrained shear strength of soil measured by penetration of a T-bar test

$t_{\text {scrape }}$ scrape depth

$x_{\mathrm{s} 1}, x_{\mathrm{s} 2}$ moment arms of $W_{1}^{\prime}, W_{2}^{\prime}$ in the upper bound solution

$W_{1}^{\prime}, W_{2}^{\prime}$ submerged (or effective) weights of soil masses per unit length in the upper bound solution

$W_{\mathrm{p}}^{\prime}$ submerged (or effective) pipe weight per unit length

$\mathrm{p}$ depth below original soil surface

$z_{\text {ahead }}$ pipe invert level relative to soil level ahead of the pipe

$z_{\text {behind }}$ pipe invert level relative to soil level behind the pipe

$z_{\text {init }}$ initial pipe embedment (measured at pipe invert) below the original soil surface

$z_{\text {invert }}$ pipe invert level relative to original soil surface

$z_{\text {startup }}$ pipe embedment (measured at pipe invert) below the original soil surface prior to lateral sweeping

$\gamma^{\prime}$ submerged (or effective) soil unit weight

$\Delta$ horizontal pipe displacement

$\mu$ friction coefficient at soil-pipe interface 